\title{
1 Broadening a SARS-CoV-1 neutralizing antibody for potent 2 SARS-CoV-2 neutralization through directed evolution
}

\section{Authors}

4 Fangzhu Zhao ${ }^{1,2,3,10}$, Meng Yuan ${ }^{4,10}$, Celina Keating ${ }^{1,2,3,10}$, Namir Shaabani ${ }^{1,10}$, Oliver Limbo ${ }^{2,5}$, 5 Collin Joyce ${ }^{1,2,3}$, Jordan Woehl ${ }^{2,5}$, Shawn Barman ${ }^{1,2,3}$, Alison Burns ${ }^{1,2,3}$, Xueyong Zhu ${ }^{4}$, Michael 6 Ricciardi ${ }^{6}$, Linghang Peng ${ }^{1}$, Jessica Smith ${ }^{2,5}$, Deli Huang ${ }^{1}$, Bryan Briney ${ }^{1,3,7}$, Devin Sok ${ }^{1,2,3,5}$, David 7 Nemazee ${ }^{1}$, John R. Teijaro ${ }^{1}$, Ian A. Wilson ${ }^{2,3,4,8}$, Dennis R. Burton ${ }^{1,2,3,9}$, Joseph G. Jardine ${ }^{2,5^{*}}$

9 'Department of Immunology and Microbiology, The Scripps Research Institute, La Jolla, CA 10 92037, USA.

11 'IAVI Neutralizing Antibody Center, The Scripps Research Institute, La Jolla, CA 92037, USA.

$12{ }^{3}$ Consortium for HIVIAIDS Vaccine Development (CHAVD), The Scripps Research Institute, La 13 Jolla, CA 92037, USA.

$14{ }^{4}$ Department of Integrative Structural and Computational Biology, The Scripps Research Institute, 15 La Jolla, CA 92037, USA.

16 IAVI, New York, NY 10004, USA.

$17{ }^{6}$ Department of Pathology, George Washington University, Washington, DC 20052, USA.

$18 \quad{ }^{7}$ Center for Viral Systems Biology, The Scripps Research Institute, La Jolla, CA 92037, USA.

$19{ }^{8}$ The Skaggs Institute for Chemical Biology, The Scripps Research Institute, La Jolla, CA 92037, 20 USA.

$21 \quad{ }^{9}$ Ragon Institute of Massachusetts General Hospital, Massachusetts Institute of Technology, and 22 Harvard University, Cambridge, MA 02139, USA.

2310 These authors contributed equally to this work.

$24{ }^{*}$ Correspondence: jjardine@iavi.org (J.G.J.)

\section{ABSTRACT}

The emergence of SARS-CoV-2 underscores the need for strategies to rapidly develop neutralizing monoclonal antibodies that can function as prophylactic and therapeutic agents and

29 to help guide vaccine design. Here, we demonstrate that engineering approaches can be used to 
refocus an existing neutralizing antibody to a related but resistant virus. Using a rapid affinity maturation strategy, we engineered CR3022, a SARS-CoV-1 neutralizing antibody, to bind SARSCoV-2 receptor binding domain with $>1000$-fold improved affinity. The engineered CR3022 neutralized SARS-CoV-2 and provided prophylactic protection from viral challenge in a small animal model of SARS-CoV-2 infection. Deep sequencing throughout the engineering process paired with crystallographic analysis of an enhanced antibody elucidated the molecular mechanisms by which engineered CR3022 can accommodate sequence differences in the epitope between SARS-CoV-1 and SARS-CoV-2. The workflow described provides a blueprint for rapid broadening of neutralization of an antibody from one virus to closely related but resistant viruses.

\section{INTRODUCTION}

Following the emergence of severe acute respiratory syndrome coronavirus 2 (SARSCoV-2), a massive effort was initiated to repurpose existing or discover new antibodies against SARS-CoV-2 to use as research tools, diagnostics, and as direct medical countermeasures for prophylactic and therapeutic indications. Early repurposing efforts screened monoclonal antibodies that had previously been isolated from 2003 SARS-CoV-1 (sometimes designated as SARS-CoV) and 2008 MERS-CoV survivors against SARS-CoV-2 (Tian et al., 2020), but none of the existing antibodies were able to efficiently neutralize this novel virus. In parallel, multiple groups worked to isolate antibodies from SARS-CoV-2 infected humans or from animals immunized with SARS-CoV-2 spike (S) proteins (Hansen et al., 2020; Ju et al., 2020; Pinto et al., 2020; Robbiani et al., 2020; Rogers et al., 2020; Wrapp et al., 2020). Although various approaches were used in the antibody discovery process, most utilized an antigen-specific B cell sorting strategy to isolate binding antibodies followed by an in vitro neutralization assay to identify the neutralizing subset. This antibody discovery process has been widely used to identify HIV neutralizing antibodies and extensively refined and streamlined over the last decade to the point where it is possible to progress from biological samples to recombinantly produced antibodies ready for validation in 1-2 weeks (Huang et al., 2013, 2014; Rogers et al., 2020; Sok et al., 2014). The two major bottlenecks in this process currently are: 1) access to high quality peripheral blood mononuclear cell (PBMC) samples for antigen-specific B cell sorting and 2) the identification of lead therapeutic candidates that have both the desired neutralization function and biochemical developability properties that are amenable to large-scale manufacturing and formulation. Access 
samples were not available in the United States and Europe because of shipping and/or biosafety restrictions.

Here we explore a hybrid "refocusing" approach that is a blend between conventional discovery and repurposing, where an existing neutralizing antibody is engineered to target a related, but resistant virus. As a case study, we selected CR3022, a SARS-CoV-1 neutralizing monoclonal antibody isolated in 2006 from a convalescent donor (ter Meulen et al., 2006). At the onset of the pandemic, CR3022 received considerable attention because it was shown to crossreact with SARS-CoV-2 (Tian et al., 2020). Several groups tested whether CR3022 could neutralize SARS-CoV-2, and most observed either no neutralization or only partial neutralization at the highest antibody concentration (Anand et al., 2020; Atyeo et al., 2021; Manenti et al., 2020; Wu et al., 2020b; Yuan et al., 2020a; Zhou et al., 2020), although one group did report neutralizing activity in their assay (Huo et al., 2020). A crystal structure revealed that CR3022 recognizes an epitope outside of the ACE2 binding site that is highly conserved between SARS-CoV-1 and SARS-CoV-2 (Yuan et al., 2020a) with only four amino acid differences located in or around the CR3022 epitope. Reversion of one of these four mutations, P384A, was shown to be responsible for the 100-fold reduction in binding affinity for CR3022 to the novel SARS-CoV-2 (Wu et al., 2020a). These findings are consistent with other documented examples of viral escape from neutralizing antibodies (nAbs), where small changes in the antibody epitope are sufficient to reduce antibody binding below the requisite threshold to achieve effective neutralization (Bates et al., 2014). To address this, we wanted to explore whether engineering approaches can be used to retarget the SARS-CoV-1 nAb CR3022 to the corresponding epitope on SARS-CoV-2.

\section{RESULTS}

\section{Engineering of SARS-CoV-1 nAb CR3022 to efficiently recognize SARS-CoV-2}

To engineer CR3022 variants with higher affinity for SARS-CoV-2 S protein, we utilized a rapid antibody affinity maturation strategy that we developed called $\underline{\text { Synthetic }} \underline{\text { Antibody }}$ Maturation

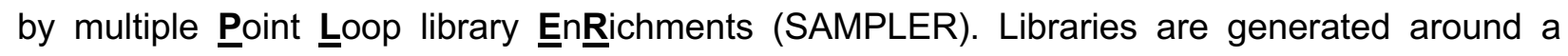
starting antibody sequence by introducing single mutations within the complementaritydetermining region (CDR) loops. These variant libraries are then displayed on the surface of yeast as molecular Fab and screened with fluorescence-activated cell sorting (FACS) to isolate clones with improved affinity for the target antigen (Figure 1A). During the library generation, the diversity 
mutation is explicitly synthesized so the library is free of unwanted mutations like cysteines or methionines and mutations that would introduce $\mathrm{N}$-linked glycan motifs. Each CDR loop library contains 100-200 unique variants, depending on the length of the loop, and when the CDR1/2/3 libraries are combined, the resulting combinatorial library contains 3-4 million unique sequences, each with up to 3 mutations from the parental CR3022 heavy chain (HC) or light chain (LC) sequence (Figure 1A). This strategy efficiently samples a large theoretical search space around the starting antibody sequence and allows for the screening of synergistic mutations between CDR loops, as it has been shown that affinity enhancing mutations can be destabilizing and require compensatory stabilizing mutations (Julian et al., 2017). Overall, this rational CDR synthesis reduces the theoretical diversity by 6 -fold compared to using NNK by removing the redundancy of the overrepresented amino acids and removing unwanted mutations (Table S1).

Initially, two libraries were generated-one library with mutations in the $\mathrm{HC}$ paired with unmodified LC ( $\mathrm{HC}$ library) and one library with mutations in the LC that was paired with the unmodified HC (LC library) and displayed on the surface of yeast (Figure 1A). Each library was sorted four times against SARS-CoV-2 receptor binding domain (RBD) to enrich for variants with higher affinity for the protein (Figure S1). In sorts 1, 2 and 4, cells were labeled with non-saturating concentrations of biotinylated SARS-CoV-2 RBD and the top 5-10\% of RBD-binding cells, normalized for Fab surface display, were collected to enrich for HC or LC sequences with increased affinity for SARS-CoV-2 RBD (Figure S2). In sort 3, a negative selection was used to deplete polyreactive clones, where cells were labeled with a biotinylated preparation of detergent solubilized HEK293 membrane proteins (Figure S1) (Xu et al., 2013). After the four selections, the antibody display vectors from the $\mathrm{HC}$ and LC libraries were harvested and the region encoding the heavy and light chain was amplified and combined into a new combinatorial heavy and light chain library ( $H / L$ library) that sampled diversity in both chains (Figure $1 A)$. The $H / L$ library was screened with the same four-round selection protocol to identify the optimal combination of mutations in the heavy and light chains. In total, it took just under one month to complete all three rounds of SAMPLER optimization (Figure S1).

Following each round of SARS-CoV-2 selection, plasmid DNA encoding the HC and LC regions was amplified and deep sequenced. The $\mathrm{HC}$ library showed a strong preference for an S55G mutation (Kabat numbering) in CDRH2, appearing in 57\% of sequences after sort 1 and $98 \%$ of sequences after sort 4 (Figure 1B). In CDRH3, an S96G mutation was observed in $36 \%$ of sequences. The mutations in CDRH1 were largely localized to the F29 and T31 positions, with $65 \%$ and $33 \%$ enriched mutation frequency respectively, but multiple mutations were allowed at each one of those positions. The LC library showed strong enrichment for a tyrosine to tryptophan 
127 mutation at position $\mathrm{Y} 27_{\mathrm{d}}$ residue in CDRL1, enriching to $52 \%$ of the total reads after sort 4 (Figure 1B). CDRL2 and CDRL3 showed no strong enrichments across any of the selections.

In the combinatorial H/L library, three mutations were further enriched in CR3022 HC: 98\% T31W in CDRH1, 99\% of S55G in CDRH2, and 100\% S96G in CDRH3 (Figure S3). Nevertheless, the LC remained more diverse in the $\mathrm{H} / \mathrm{L}$ library, with the $\mathrm{Y}$ to $\mathrm{W}$ mutation further enriched to $71 \%$

132 of the population at the Y27 position (Figure S3). In addition to deep sequencing of the individual 133 chains, PacBio sequencing was used to evaluate the recovered heavy/light pairs from sort 4 . The 134 overall frequencies of mutations closely matched what was observed in the individual chains, with 135 a high degree of convergence on the heavy chain and a significant level of diversity still present 136 in the light chain, with no clear evidence of evolutionary coupling within the selected $\mathrm{H} / \mathrm{L}$ chain 137 pairings (Figure 1C).

\section{Binding and neutralizing activity of eCR3022 for SARS-CoV-2}

From the sequences recovered after the final $\mathrm{H} / \mathrm{L}$ library sort, we selected 25 engineered CR3022 antibodies, named engineered (e) eCR3022.1 through eCR3022.25, to reformat for expression as human IgG1 for in-depth characterization. Because of the nature of how the $H / L$ library was constructed and the fact that there was more observed convergence in the $\mathrm{HC}$, the selected variants utilized only 5 unique HCs, while all 25 LCs were unique (Table S2). The affinities for SARS-CoV-1 RBD of all eCR3022 Abs remained the same or slightly improved compared to the parental CR3022, despite not having been included in the optimization process (Figures 2A, 2B; Table S2). The binding affinities of all eCR3022 antibodies against monomeric SARS-CoV-2 RBD increased between 100 to 1000-fold compared to the parental CR3022 by surface plasmon resonance (SPR), with equilibrium dissociation constant $\left(K_{D}\right)$ values ranging from $16 \mathrm{pM}$ to $312 \mathrm{pM}$ (Figures 2A, 2C; Table S2). The on-rate of the antibodies was nearly the same as the parental CR3022, with the affinity increases coming through a reduction in the antibody off-rate (Figure 2C, Table S2). The ELISA binding activities of the eCR3022 variants against SARS-CoV-2 S and RBD were also improved (Figure S4), showing that this increased binding to SARS-CoV-2 RBD also translated to the functional S protein. All engineered antibodies

154 showed negligible polyreactive binding across our nonspecific antigen panels (Figure S5A, S5B) 155 and were monodispersed with analytical SEC column retention times similar to other clinical mAbs 156 (Figure S5C), indicating the engineering had minimal impact on the favorable biochemical 157 properties of the parental CR3022.

158 To evaluate the effect of the affinity gains on antibody neutralization, CR3022 and all 25 159 eCR3022 variants were tested using an MLV-based pseudovirus system (Rogers et al., 2020). 
All variants showed enhanced neutralization of SARS-CoV-1, with the most potent neutralizing at $0.5 \mu \mathrm{g} / \mathrm{mL}$ compared to the parental CR3022 that neutralizes at $10.9 \mu \mathrm{g} / \mathrm{mL}$ (Figures 2D, 2E). In our assay, CR3022 failed to neutralize SARS-CoV-2 at a maximum antibody concentration of 100 $\mu \mathrm{g} / \mathrm{mL}$ (Figures 2D, 2F). In contrast, all eCR3022 antibodies were able to neutralize pseudotyped SARS-CoV-2 with a median $\mathrm{IC}_{50}$ of $1.6 \mu \mathrm{g} / \mathrm{mL}$, with the most potent neutralizing SARS-CoV-2 exhibiting an $\mathrm{IC}_{50}$ of $0.3 \mu \mathrm{g} / \mathrm{mL}$ (Figures 2D, 2F). We further tested the neutralization activity of eCR3022.7, eCR3022.10 and eCR3022.20 against the emerging variants of concern B.1.1.7 (with N501Y mutation on RBD) and B.1.351 (with K417N, E484K, N501Y mutations on RBD) variants (Tegally et al.), where the mutations are located in the receptor binding site on the RBD and are outside the CR3022 epitope. As expected, eCR3022 antibodies neutralized both viral variants with similar IC 50 to the wildtype virus SARS-CoV-2 (Figure S6). Lastly, the eCR3022 variants were able to neutralize authentic SARS-CoV-2 virus while CR3022 failed to neutralize, confirming the neutralization against authentic virus (Figure S7).

\section{Structural analysis of eCR3022.20 complexed to SARS-CoV-2 RBD}

To understand the molecular features of the affinity-matured eCR3022 antibodies that confer potent neutralization against SARS-CoV-2, we determined a crystal structure of eCR3022.20 in complex with SARS-CoV-2 RBD and Fab CC12.3 (Yuan et al., 2020b) (to aid in crystallization) to $2.85 \AA$ resolution and compared its binding with CR3022 (Yuan et al., 2020a) (Figure 3A; Figure S8; Table S3). Two copies of the eCR3022.20-RBD-CC12.3 complex were found in the crystal asymmetric unit. eCR3022.20 binds SARS-CoV-2 RBD via the same epitope as CR3022 through a nearly identical angle of approach (Yuan et al., 2020a) (Figure 3A). Furthermore, the RBD conformation bound by both antibodies are almost identical, except for two regions of the RBD (residues 365-370 and 384-390) that are displaced in eCR3022.20 compared to CR3022 (Figure 3B). However, residues in both of these regions (RBD-Y369, F377, and P384) form a hydrophobic pocket that interact with CDRH1 of these antibodies (Figures 3C-3F). $V_{H}$ T31 in CDRH1 of CR3022 (Figure 3C) is substituted by a bulky hydrophobic, aromatic residue W31, which stacks with RBD residues Y369, F377, and P384 and strengthens the interaction with this 187 hydrophobic pocket in the RBD (Figures 3D, 3E). The T31W substitution induces a 2.4- $\AA$ shift in 188 the RBD around residues $365-370$, as well as a $1.4-\AA$ shift of residues $384-390$ (Figure 3F). 189 Previously, we showed that residue 384 is an important epitope residue for CR3022 binding, 190 where a P384A mutation conferred an approximate 100-fold affinity improvement for CR3022 (Wu 191 et al., 2020a). Here, we show that a substitute paratope residue targeting this area of the epitope 
192 is able to contribute to an improvement in antibody binding and further highlights the importance of P384 as a key epitope residue for CR3022.

In addition to CDRH1, CDRH2 of both CR3022 and eCR3022.20 interact with SARS-CoV2 RBD (Figures 3G, 3H). For both antibodies, $V_{H}$ Y52 forms a hydrogen bond with the backbone amide of RBD-F377. $\mathrm{V}_{\mathrm{H}}$ D54 and E56 clamp onto RBD-K378 with two salt bridges (Figures 3G, $3 H$ ). $C D R H 2$ in both antibodies form a type-IV $\beta$ (Lewis et al., 1973) at the CDR tip, where $V_{H} S 55$ $(i+3)$ in CR3022 is substituted by a glycine in most sorted antibody variants during the process of affinity maturation (Figure 1B; Figure S9). Glycine is frequently found in $\beta$ turns due to the lack of a side chain that allows higher conformational flexibility. Indeed, glycine is the most frequent residue at the $i+3$ position of a type-IV $\beta$ turn, suggesting that it is energetically favored at this position as it can also more readily adopt a positive phi value as found here compared to S55 (Guruprasad and Rajkumar, 2000). For the light-chain residues, $V_{L}$ Y 31 and S99 are mutated to W31 and K99 in eCR3022.20 (Figures 3I, 3J). While $V_{L}$ W31 retains hydrophobic interactions with RBD-Y380, P412, and F429, $V_{L}$ K99 is able to form a cation- $\pi$ interaction with W31, which stabilizes the interaction between CDRs L1 and L3 and may reduce the entropy of its interaction with the RBD.

\section{Protection by eCR3022 against SARS-CoV-2 challenge in a small animal model}

Upon developing a CR3022 variant capable of neutralizing SARS-CoV-2, we sought to evaluate whether this engineered antibody could provide prophylactic protection against viral

211 challenge in the Syrian hamster model. Based on the neutralization and biophysical data, 212 eCR3022.7 was selected as our initial candidate antibody to evaluate. Groups of six hamsters 213 received an intraperitoneal infusion $10 \mathrm{mg}, 2 \mathrm{mg}, 0.5 \mathrm{mg}$, or $0.125 \mathrm{mg}$ of eCR3022.7 per animal 214 to evaluate dose-dependent protection. Another group received $10 \mathrm{mg}$ of the parental CR3022 215 antibody and a control group received $10 \mathrm{mg}$ of an anti-dengue isotype matched antibody. Three 216 days post infusion, sera were collected from each animal to determine antibody titer at the time 217 of viral challenge. Animals were then challenged with $1 \times 10^{5}$ plaque forming units (PFU) of SARS218 CoV-2 (USA-WA1/2020) by intranasal administration. The hamsters were weighed daily as a 219 measure of disease due to infection and sera were collected from all animals at the conclusion of 220 the experiment on day 7. Hamsters have been shown to clear SARS-CoV-2 infection after 7 days 221 (Sia et al., 2020), so a replicate of the original experiment was performed with six additional 222 animals in which lung tissue was collected on day 4 to accurately measure replicative viral load 223 amongst the groups (Figure 4A). 
The groups receiving the highest doses of eCR3022.7 of $10 \mathrm{mg}$ or $2 \mathrm{mg}$ were largely protected from viral challenge, exhibiting either no weight loss or $3 \%$ weight loss, respectively, at the end of the 7-day experiment (Figure 4B; Figure S10). In contrast, the group that received 10 mg of the original CR3022 antibody lost $11 \%$ of body weight, comparable to the control group that received $10 \mathrm{mg}$ of Den3. The groups that received $0.5 \mathrm{mg}$ or $0.125 \mathrm{mg}$ eCR3022.7 on average lost slightly less weight than the control group but the difference was not significant (Table S4). Lung viral titers were assessed from the second group of animals by plaque assay (Figure 4C). Equivalent viral loads were measured between the control Den3 and original CR3022 groups with average of $4.0 \times 10^{6} \mathrm{PFU} / \mathrm{mL}$ and $6.8 \times 10^{5} \mathrm{PFU} / \mathrm{mL}$, respectively (Table S4). In contrast, the groups that received $10 \mathrm{mg}$ or $2 \mathrm{mg}$ doses of eCR3022.7 had $7.0 \times 10^{4} \mathrm{PFU} / \mathrm{mL}$ and $8.7 \times 10^{4}$ PFU/mL, respectively, more than 2 logs lower than the Den3 control. The reduced SARS-CoV-2 viral lung titers and maintenance of body weight following challenge in the animals receiving either $10 \mathrm{mg}$ or $2 \mathrm{mg}$ doses prophylactically of eCR3022.7 demonstrate that the in vitro neutralization potency translates to in vivo protection. Serum antibody concentrations were measured both at the time of challenge and the end of the study. The $10 \mathrm{mg} \mathrm{eCR} 0322.7$ and $10 \mathrm{mg}$ CR3022 groups had an equivalent amount of antibody present at the time of injection as well as equivalent decay by day 7 , confirming that the observed protection differences are not attributable to different pharmacokinetic properties of the two antibodies (Figure 4D, Figure S10B).

\section{2}

\section{DISCUSSION}

Antibody refocusing serves as a novel approach to generate neutralizing antibodies

244 against novel viruses or viral variants, provided that a neutralizing antibody against a closely 245 related virus is available. In this case study, we successfully re-engineered a SARS-CoV-1 nAb, 246 CR3022, so that it now potently neutralized both SARS-CoV-1 and SARS-CoV-2. eCR3022 247 variants with $>1000$-fold enhanced affinity for SARS-CoV-2 RBD were generated while 248 maintaining their biochemically favorable developability profile. The enhanced affinity conferred 249 the ability to potently neutralize SARS-CoV-2 and protect from viral challenge in a small animal 250 model. In fact, the eCR3022 variants now neutralize SARS-CoV-2 more potently than the parental 251 CR3022 neutralizes SARS-CoV-1. These findings are consistent with previous studies showing 252 a relationship between antibody/antigen binding affinity for S protein and neutralization potency. 253 However, this is the first instance that we are aware of where an antibody has been specifically 254 retargeted or optimized to a novel related virus. Although this refocusing strategy likely will not be 255 effective when the antibody epitope is substantially different between viruses (Figure S11), the 
potential pool of starting antibodies continues to expand as more neutralizing antibodies are discovered against different viruses. We also note that the use of on-chip DNA synthesis to rationally produce the CDR libraries used in our SAMPLER optimization allowed us to efficiently cover a large portion of the theoretical search space within the antibody paratope, effectively achieving these affinity gains in a two-step process. Given that the affinity engineering described can be done in less than one month and does not require access to PBMC samples from immunized or infected donors or structural information on the antibody/antigen interaction, the approach could be used in conjunction with conventional antibody discovery as a rapid response to future outbreaks of pandemic concern.

\section{REFERENCES}

267 Adams, P.D., Afonine, P.V., Bunkóczi, G., Chen, V.B., Davis, I.W., Echols, N., Headd, J.J., 268 Hung, L.-W., Kapral, G.J., Grosse-Kunstleve, R.W., et al. (2010). PHENIX: a comprehensive 269 Python-based system for macromolecular structure solution. Acta Crystallogr. Sect. D, Biol. 270 Crystallogr. 66, 213-221.

271 Anand, S.P., Chen, Y., Prévost, J., Gasser, R., Beaudoin-Bussières, G., Abrams, C.F., Pazgier, 272 M., and Finzi, A. (2020). Interaction of Human ACE2 to Membrane-Bound SARS-CoV-1 and 273 SARS-CoV-2 S Glycoproteins. Viruses 12, 1104.

274 Atyeo, C., Slein, M.D., Fischinger, S., Burke, J., Schäfer, A., Leist, S.R., Kuzmina, N.A., Mire,

275 C., Honko, A., Johnson, R., et al. (2021). Dissecting strategies to tune the therapeutic potential 276 of SARS-CoV-2-specific monoclonal antibody CR3022. JCI Insight 6, e143129.

277 Bates, J.T., Keefer, C.J., Slaughter, J.C., Kulp, D.W., Schief, W.R., and Crowe, J.E. (2014).

278 Escape from neutralization by the respiratory syncytial virus-specific neutralizing monoclonal 279 antibody palivizumab is driven by changes in on-rate of binding to the fusion protein. Virology 280 454-455, 139-144.

281 Bushnell, B., Rood, J., and Singer, E. (2017). BBMerge - accurate paired shotgun read merging 282 via overlap. PLoS One 12, e0185056.

283 Crooks, G.E., Hon, G., Chandonia, J.M., and Brenner, S.E. (2004). WebLogo: a sequence logo 284 generator. Genome Res. 14, 1188-1190.

285 Emsley, P., Lohkamp, B., Scott, W.G., and Cowtan, K. (2010). Features and development of 286 Coot. Acta Crystallogr. Sect. D, Biol. Crystallogr. 66, 486-501.

287 Guruprasad, K., and Rajkumar, S. (2000). Beta-and gamma-turns in proteins revisited: a new 288 set of amino acid turn-type dependent positional preferences and potentials. J. Biosci. 25, 143- 
156.

290 Hansen, J., Baum, A., Pascal, K.E., Russo, V., Giordano, S., Wloga, E., Fulton, B.O., Yan, Y., 291 Koon, K., Patel, K., et al. (2020). Studies in humanized mice and convalescent humans yield a 292 SARS-CoV-2 antibody cocktail. Science 369, 1010-1014.

293 Huang, J., Doria-Rose, N.A., Longo, N.S., Laub, L., Lin, C.-L., Turk, E., Kang, B.H., Migueles, 294 S.A., Bailer, R.T., Mascola, J.R., et al. (2013). Isolation of human monoclonal antibodies from 295 peripheral blood B cells. Nat. Protoc. 8, 1907-1915.

296 Huang, J., Kang, B.H., Pancera, M., Lee, J.H., Tong, T., Feng, Y., Imamichi, H., Georgiev, I.S., 297 Chuang, G.-Y., Druz, A., et al. (2014). Broad and potent HIV-1 neutralization by a human antibody that binds the gp41-gp120 interface. Nature 515, 138-142.

299 Huo, J., Zhao, Y., Ren, J., Zhou, D., Duyvesteyn, H.M.E., Ginn, H.M., Carrique, L., Malinauskas, T., Ruza, R.R., Shah, P.N.M., et al. (2020). Neutralization of SARS-CoV-2 by Destruction of the Prefusion Spike. Cell Host Microbe 28, 497. Ju, B., Zhang, Q., Ge, J., Wang, R., Sun, J., Ge, X., Yu, J., Shan, S., Zhou, B., Song, S., et al. (2020). Human neutralizing antibodies elicited by SARS-CoV-2 infection. Nature 584, 115-119. Julian, M.C., Li, L., Garde, S., Wilen, R., and Tessier, P.M. (2017). Efficient affinity maturation of antibody variable domains requires co-selection of compensatory mutations to maintain thermodynamic stability. Sci. Rep. 7, 45259. Krissinel, E., and Henrick, K. (2007). Inference of macromolecular assemblies from crystalline state. J. Mol. Biol. 372, 774-797. Lan, J., Ge, J., Yu, J., Shan, S., Zhou, H., Fan, S., Zhang, Q., Shi, X., Wang, Q., Zhang, L., et al. (2020). Structure of the SARS-CoV-2 spike receptor-binding domain bound to the ACE2 receptor. Nature 581, 215-220. Lewis, P.N., Momany, F.A., and Scheraga, H.A. (1973). Chain reversals in proteins. Biochimica et Biophysica Acta (BBA) - Protein Structure 303, 211-229.

314 Li, A., Acevedo-Rocha, C.G., Sun, Z., Cox, T., Xu, J.L., and Reetz, M.T. (2018). Beating Bias in 315 the Directed Evolution of Proteins: Combining High-Fidelity on-Chip Solid-Phase Gene 316 Synthesis with Efficient Gene Assembly for Combinatorial Library Construction. Chembiochem 317 19, 221-228.

318 Manenti, A., Maggetti, M., Casa, E., Martinuzzi, D., Torelli, A., Trombetta, C.M., Marchi, S., and 319 Montomoli, E. (2020). Evaluation of SARS-CoV-2 neutralizing antibodies using a CPE-based 320 colorimetric live virus micro-neutralization assay in human serum samples. J. Med. Virol. 92, 2096-2104. 
McCoy, A.J., Grosse-Kunstleve, R.W., Adams, P.D., Winn, M.D., Storoni, L.C., and Read, R.J. (2007). Phaser crystallographic software. J Appl Crystallogr 40, 658-674. ter Meulen, J., van den Brink, E.N., Poon, L.L.M., Marissen, W.E., Leung, C.S.W., Cox, F., Cheung, C.Y., Bakker, A.Q., Bogaards, J.A., van Deventer, E., et al. (2006). Human monoclonal antibody combination against SARS coronavirus: synergy and coverage of escape mutants. PLoS Med. 3, e237.

Otwinowski, Z., and Minor, W. (1997). Processing of X-ray diffraction data collected in oscillation mode. Meth. Enzymol. 276, 307-326.

Pinto, D., Park, Y.-J., Beltramello, M., Walls, A.C., Tortorici, M.A., Bianchi, S., Jaconi, S., Culap, K., Zatta, F., De Marco, A., et al. (2020). Cross-neutralization of SARS-CoV-2 by a human monoclonal SARS-CoV antibody. Nature 583, 290-295.

Robbiani, D.F., Gaebler, C., Muecksch, F., Lorenzi, J.C.C., Wang, Z., Cho, A., Agudelo, M., Barnes, C.O., Gazumyan, A., Finkin, S., et al. (2020). Convergent antibody responses to SARSCoV-2 in convalescent individuals. Nature 584, 437-442. G., Woehl, J., et al. (2020). Isolation of potent SARS-CoV-2 neutralizing antibodies and protection from disease in a small animal model. Science 369, 956-963. open source tool for metagenomics. PeerJ 4, e2584.

Sia, S.F., Yan, L.-M., Chin, A.W.H., Fung, K., Choy, K.-T., Wong, A.Y.L., Kaewpreedee, P., Perera, R.A.P.M., Poon, L.L.M., Nicholls, J.M., et al. (2020). Pathogenesis and transmission of SARS-CoV-2 in golden hamsters. Nature 583, 834-838.

Sok, D., van Gils, M.J., Pauthner, M., Julien, J.-P., Saye-Francisco, K.L., Hsueh, J., Briney, B., Lee, J.H., Le, K.M., Lee, P.S., et al. (2014). Recombinant HIV envelope trimer selects for quaternary-dependent antibodies targeting the trimer apex. Proc. Natl. Acad. Sci. USA 111,

348 Tegally, H., Wilkinson, E., Giovanetti, M., Iranzadeh, A., Fonseca, V., Giandhari, J., Doolabh, D., Pillay, S., San, E.J., Msomi, N., et al. Detection of a SARS-CoV-2 variant of concern in South Africa. Nature 592, 438-443.

352 (2020). Potent binding of 2019 novel coronavirus spike protein by a SARS coronavirus-specific 353 human monoclonal antibody. Emerg. Microbes Infect. 9, 382-385.

354 Wang, B., DeKosky, B.J., Timm, M.R., Lee, J., Normandin, E., Misasi, J., Kong, R., McDaniel, 
J.R., Delidakis, G., Leigh, K.E., et al. (2018). Functional interrogation and mining of natively paired human VH:VL antibody repertoires. Nat. Biotechnol. 36, 152-155.

Wrapp, D., De Vlieger, D., Corbett, K.S., Torres, G.M., Wang, N., Van Breedam, W., Roose, K., van Schie, L., VIB-CMB COVID-19 Response Team, Hoffmann, M., et al. (2020). Structural Basis for Potent Neutralization of Betacoronaviruses by Single-Domain Camelid Antibodies. Cell 181, 1004-1015.e15.

Wu, N.C., Yuan, M., Bangaru, S., Huang, D., Zhu, X., Lee, C.-C.D., Turner, H.L., Peng, L., Yang, L., Burton, D.R., et al. (2020a). A natural mutation between SARS-CoV-2 and SARS-CoV determines neutralization by a cross-reactive antibody. PLoS Pathog. 16, e1009089. Wu, Y., Li, C., Xia, S., Tian, X., Kong, Y., Wang, Z., Gu, C., Zhang, R., Tu, C., Xie, Y., et al. (2020b). Identification of Human Single-Domain Antibodies against SARS-CoV-2. Cell Host Microbe 27, 891-898.e5. Xu, Y., Roach, W., Sun, T., Jain, T., Prinz, B., Yu, T.-Y., Torrey, J., Thomas, J., Bobrowicz, P., Vásquez, M., et al. (2013). Addressing polyspecificity of antibodies selected from an in vitro yeast presentation system: a FACS-based, high-throughput selection and analytical tool. Protein Eng Des Sel 26, 663-670. (2020a). A highly conserved cryptic epitope in the receptor binding domains of SARS-CoV-2 and SARS-CoV. Science 368, 630-633. Yuan, M., Liu, H., Wu, N.C., Lee, C.-C.D., Zhu, X., Zhao, F., Huang, D., Yu, W., Hua, Y., Tien, H., et al. (2020b). Structural basis of a shared antibody response to SARS-CoV-2. Science 369, 1119-1123. Zhou, T., Tsybovsky, Y., Gorman, J., Rapp, M., Cerutti, G., Chuang, G.-Y., Katsamba, P.S., Sampson, J.M., Schön, A., Bimela, J., et al. (2020). Cryo-EM Structures of SARS-CoV-2 Spike without and with ACE2 Reveal a pH-Dependent Switch to Mediate Endosomal Positioning of Receptor-Binding Domains. Cell Host Microbe 28, 867-879.e5.

\section{ACKNOWLEDGEMENTS}


was partially funded by IAVI with the generous support of USAID and other donors; a full list of IAVI donors is available at www.iavi.org. This work was supported by the Bill and Melinda Gates Foundation OPP1170236 and INV-004923 INV (I.A.W., D.R.B.). D.H. and D.N. were supported by R01Al132317. Use of the SSRL, SLAC National Accelerator Laboratory, is supported by the U.S. Department of Energy, Office of Science, Office of Basic Energy Sciences under Contract No. DE-AC02-76SF00515. The SSRL Structural Molecular Biology Program is supported by the

392 DOE Office of Biological and Environmental Research, and by the National Institutes of Health, 393 National Institute of General Medical Sciences (including P41GM103393).

\section{AUTHOR CONTRIBUTIONS}

395 F.Z., C.K., J.G.J. designed the experiments. J.G.J. designed the synthetic antibody library, F.Z., 396 S.B. and M.J.R. performed the yeast library display and FACS selection. F.Z. and S.B. prepped 397 the yeast library DNA and deep sequenced. J.S. analyzed the deep sequencing results and C.J. 398 analyzed the PacBio sequencing results. F.Z., O.L., S.B., and A.B. expressed and purified the 399 antibodies. J.W. performed the SPR assay. F.Z., O.L. S.B., and A.B. carried out the pseudovirus 400 neutralization assays. S.P. and D.H. generated SARS-CoV-2 mutant virus constructs. N.S and 401 D.H. performed authentic SARS-CoV-2 neutralization assay. M.Y. and O.L. expressed and 402 purified the recombinant SARS-CoV-2 S and RBD proteins. F.Z., S.B. A.B. performed binding 403 assays, and biophysical analysis assays. M.Y., X.Z., and I.A.W. crystallized eCR3022.20 and 404 performed structure determination and analysis. C.K. and N.S. performed the hamster protection 405 study and measured the viral load. F.Z., M.Y., C.K., I.A.W., D.R.B. and J.G.J. wrote the 406 manuscript, and all authors reviewed and edited the manuscript. 


\section{Main Text Figures}

A
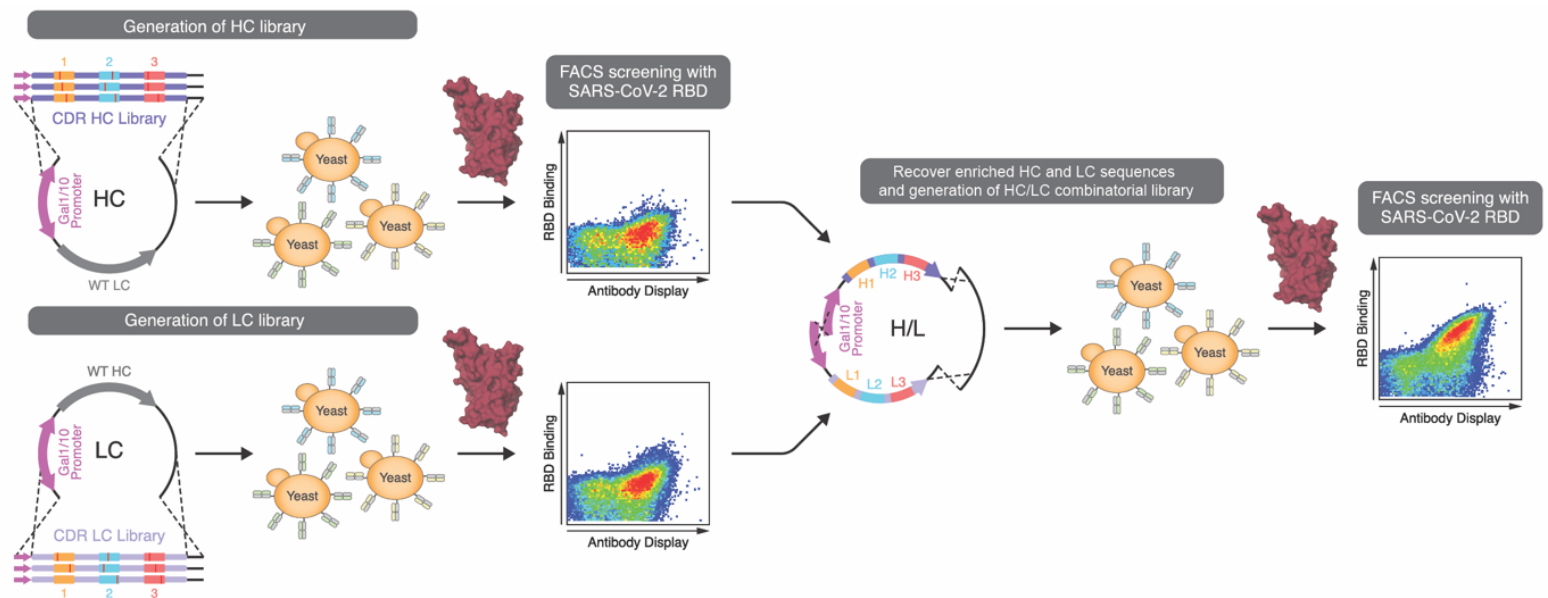

B

CR3022 HC Library

CR3022 LC Library

C
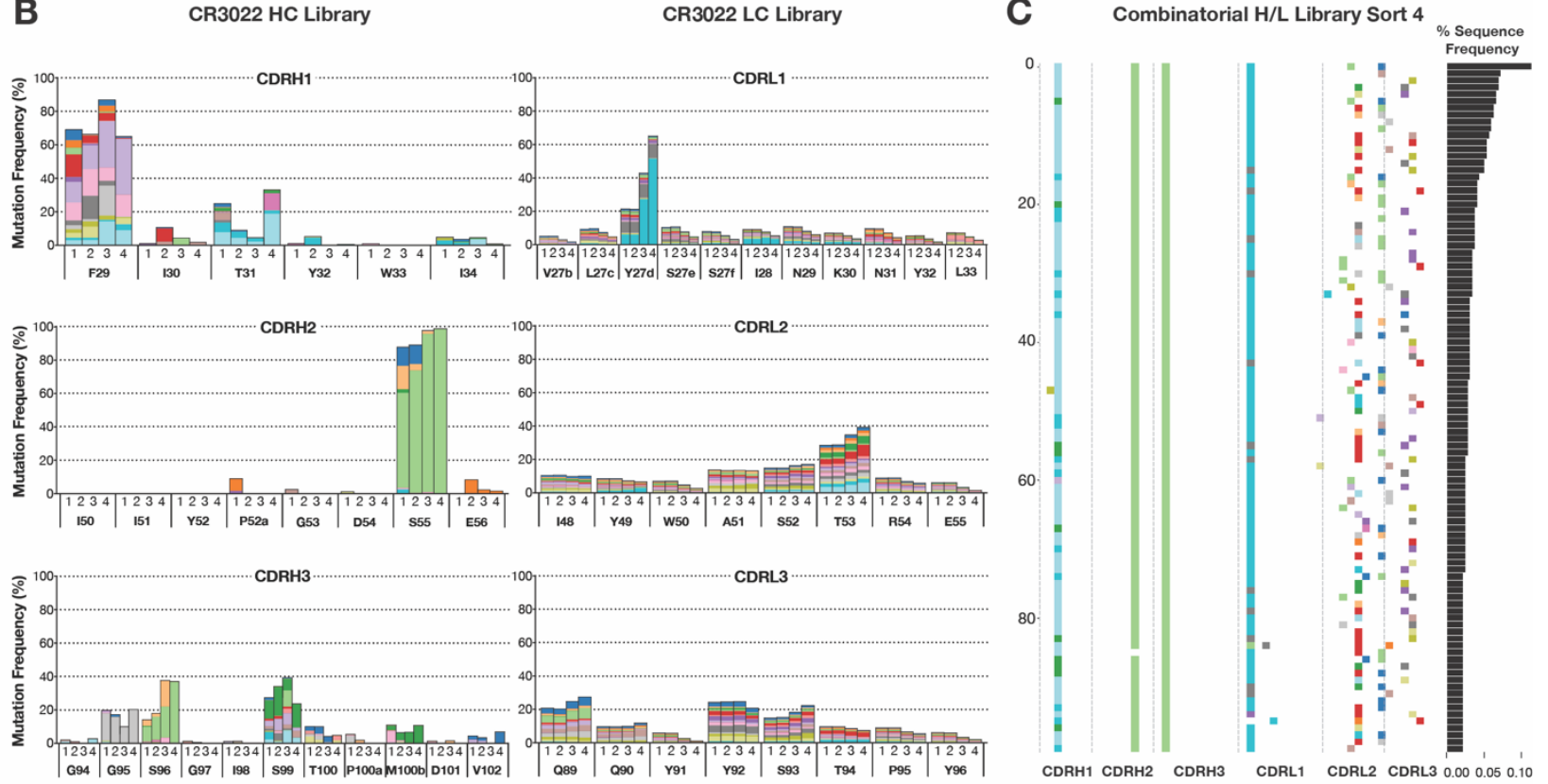

Figure 1. Engineering CR3022 to increase binding affinity to SARS-CoV-2 RBD using SAMPLER (A) A synthetic CR3022 antibody library with single mutation at each CDR loop was displayed as molecular Fab on the surface of yeast cells. The CR3022 HC library with up to three mutations was paired with the original LC while LC library was paired with the original HC. After FACS selection by SARS-CoV-2 RBD, the HC library and LC library were amplified and combined into combinatorial $\mathrm{H} / \mathrm{L}$ library and further selected for high binding clones by SARS-CoV-2 RBD.

416 Enriched clones with high binding affinities were reformatted and expressed as human $\operatorname{lgG}$. (B)

417 After each round of selection with a total of four FACS sorts, plasmid DNA from each sort was 
418 prepped and deep sequenced. Enriched mutations for each residue at CDR loop in HC library 419 (left) and LC library (right) relative to parental CR3022 sequence were analyzed and colored 420 according to the key. (C) Locations of mutations (colored according to the key) seen in the top 421100 most frequent sequences recovered from long-read next-generation sequencing of enriched $422 \mathrm{H} / \mathrm{L}$ pairs in the CR3022 combinatorial H/L library after sort 4. 


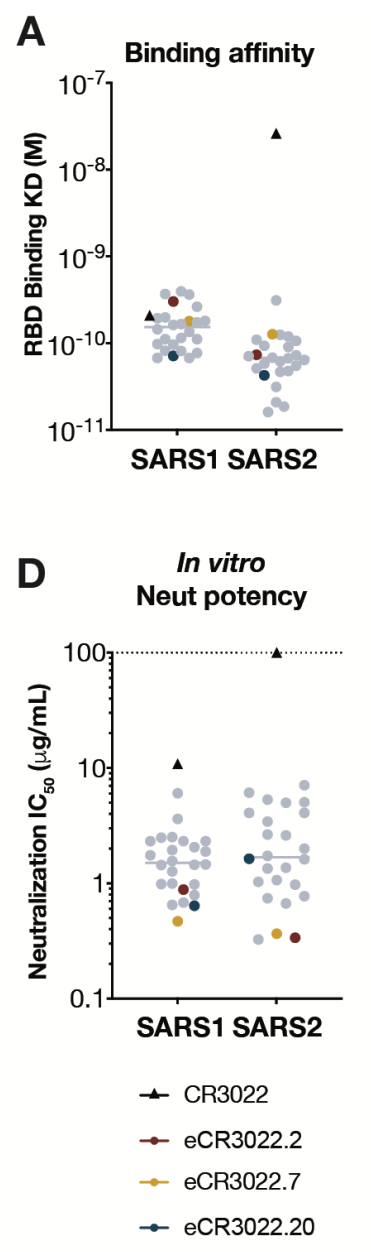

423

424

425

426

427

428

429

430

431

432

433

434

435

436

437 (F).
B

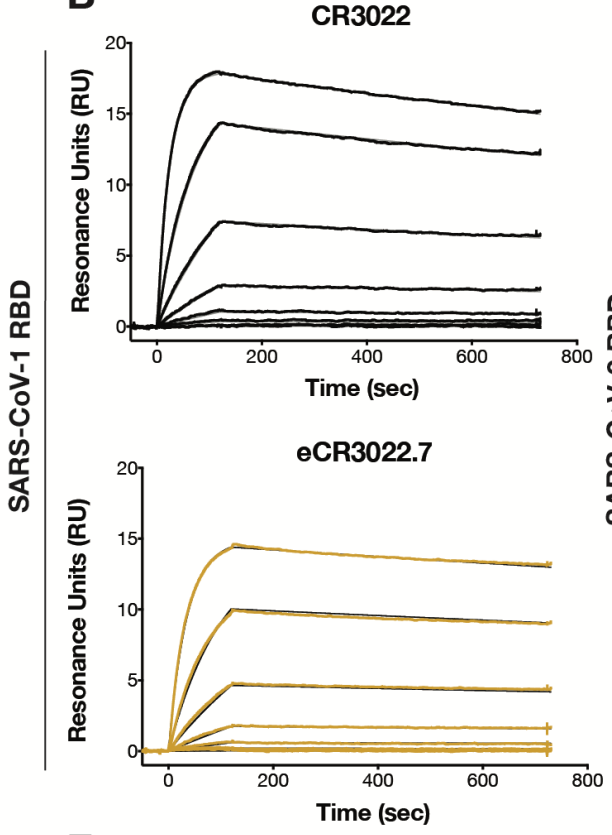

E

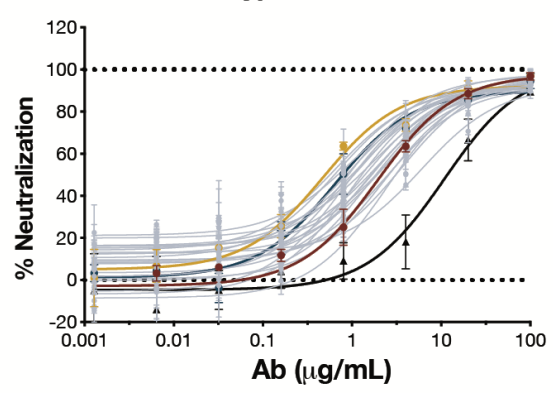

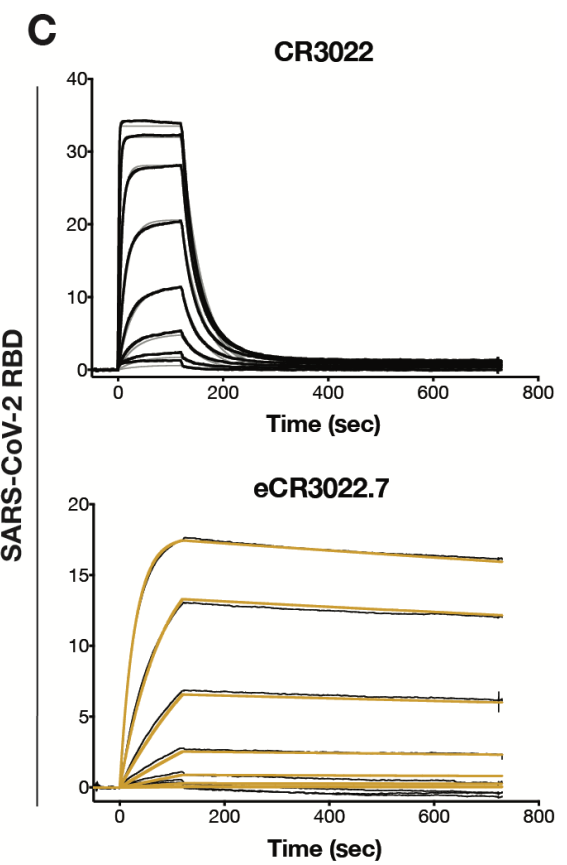

$\mathbf{F}$

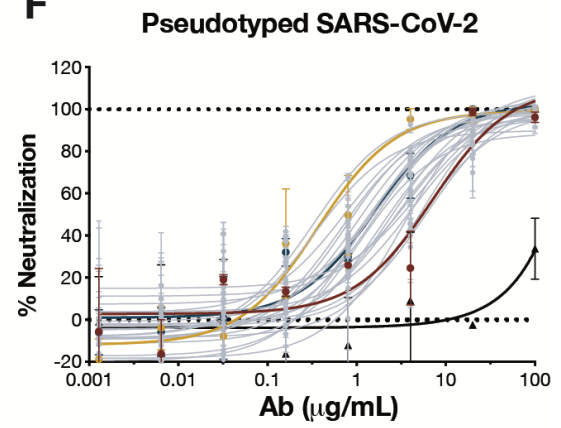

Figure 2. Engineered eCR3022 variants with over 100-fold improved binding affinity for SARS-CoV-2 RBD potently neutralize SARS-CoV-2. (A) Binding affinity (KD) of parental and enhanced eCR3022 antibodies against SARS-CoV-1 and SARS-CoV-2 RBD by surface plasmon resonance (SPR). Parental CR3022 is colored in black and represented as a triangle, eCR3022 variants are in grey whereas eCR3022.2, eCR3022.7, eCR3022.20 are highlighted in colors according to the key. (B) SPR curves of parental CR3022 (top) and eCR3022.7 (bottom) binding to SARS-CoV-1 RBD. (C) SPR curves of parental CR3022 (top) and eCR3022.7 (bottom) binding to SARS-CoV-2 RBD. Antibodies were captured via Fc-capture to an anti-human IgG Fc antibody and varying concentrations of SARS-CoV-1 or SARS-CoV-2 RBD were injected using a multicycle method. Association and dissociation rate constants calculated through a 1:1 Langmuir binding model using the BIAevaluation software. (D) Neutralization $\mathrm{IC}_{50}$ S of parental CR3022 and eCR3022 antibodies against SARS-CoV-1 and SARS-CoV-2 pseudoviruses. (E-F) Neutralization curves of parental CR3022 and eCR3022 antibodies against SARS-CoV-1 (E) and SARS-CoV-2 
A

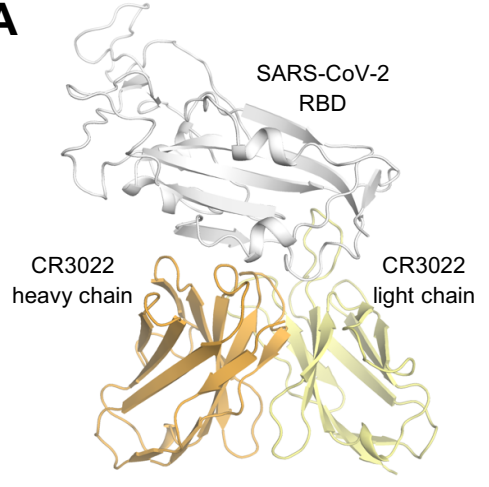

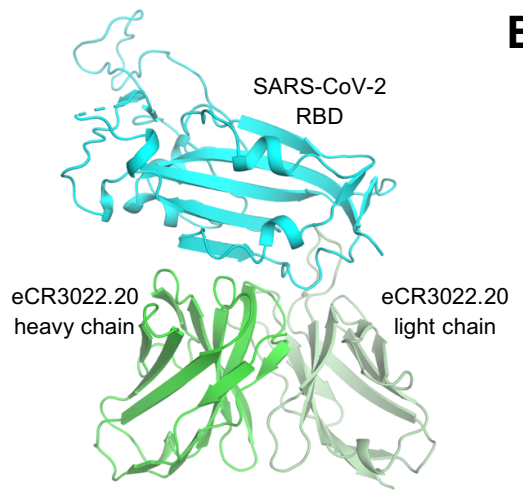
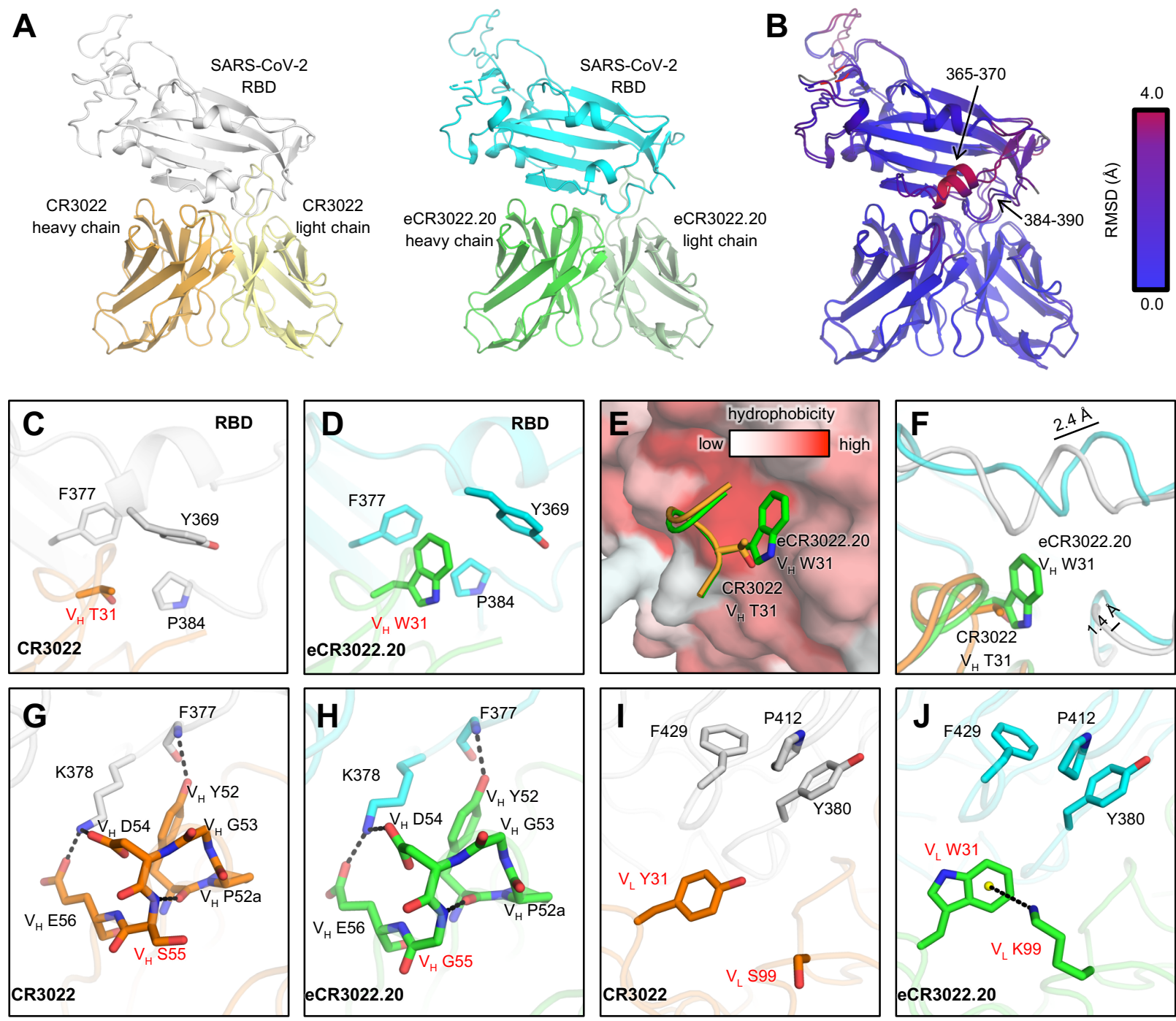

439

Figure 3. Crystal structure of eCR3022.20 in complex with SARS-CoV-2 RBD. Our previous

crystal structure of SARS-CoV-2 RBD in complex with CR3022 is shown for comparison (PDB: 6W41) (Yuan et al., 2020a). Hydrogen bonds and salt bridges are represented by black dashed lines. Residues that differ between the two antibodies are highlighted in red letters. (A) CR3022 and eCR3022.20 bind to SARS-CoV-2 RBD via the same binding mode. Left, crystal structure of SARS-CoV-2 RBD (white) in complex with CR3022 (heavy and light chains are shown in orange and light yellow, respectively). Right, crystal structure of SARS-CoV-2 RBD (cyan) in complex with eCR3022.20 (heavy and light chains are shown in green and olive, respectively). Antibody constant domains are omitted here for clarity. Antibody CC12.3 (Yuan et al., 2020b) that was used to aid in the crystallization of the RBD/eCR3022.20 complex is shown in Figure S8. (B) Superimposition of structures RBD/CR3022 and RBD/eCR3022.20. Structural differences are color-coded by their Root Mean Square Deviation (RMSD). (C-F) Comparison between the 
451 paratope $V_{H}$ T31 in CR3022 and its counterpart $V_{H} W 31$ in eCR3022.20. (E) $V_{H} T 31 / W 31$ interact 452 with a hydrophobic pocket in the SARS-CoV-2 RBD. (G-H) Interactions between CDR H2 of (G) 453 CR3022 and (H) eCR3022.20 with the SARS-CoV-2 RBD. (I-J) VL Y31/S99 in CR3022 are 454 substituted by W31/K99 in eCR3022.20. (J) VL W31 and K99 in eCR3022.20 form a cation455 interaction. The 6-carbon aromatic ring center is represented by a yellow sphere. 

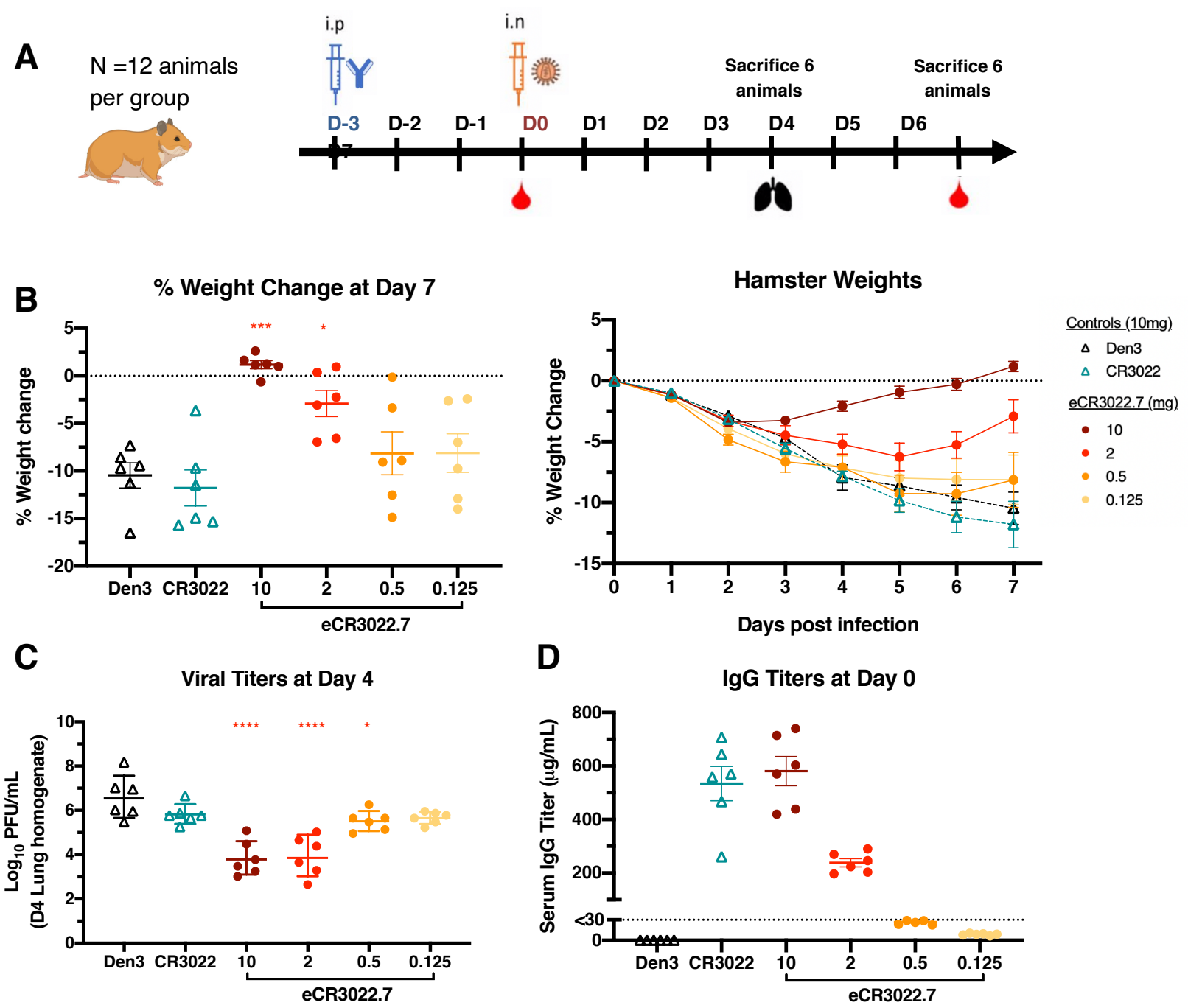

Figure 4. A non-neutralizing mAb can be engineered to become a nAb against SARS-CoVengineered mAb eCR3022.7 was administered at a starting dose of either $10 \mathrm{mg}$ per animal, 2 $\mathrm{mg}$ per animal, $0.5 \mathrm{mg}$ per animal or $0.125 \mathrm{mg}$ per animal. Control animals received $10 \mathrm{mg}$ of Den3 or $10 \mathrm{mg}$ of original mAb CR3022. Each group of 12 animals was challenged intranasally (i.n.) 72 hours after infusion with $1 \times 10^{5}$ PFU of SARS-CoV-2. Serum was collected at the time of challenge (day 0 ) and upon completion of the experiment (day 7). Animal weight was monitored as an indicator of disease progression. Six hamsters were sacrificed on day 4 and lung tissue was collected for viral burden assessment and the remaining hamsters were sacrificed on day 7 . (B) Percent weight change was calculated from the day of infection (day 0 ) for all animals. (C) 467 Viral load, as quantitated by live virus plaque assay on Vero E6 cells from lung tissue 468 homogenate. Error bars represent geometric standard deviations of the geometric mean. (D) 469 Serum titers of the passively administered mAb, as assessed by ELISA at the time of challenge 
470 (72 hours after intraperitoneal (i.p.) administration). Statistical significance $(p<0.05)$ of groups in 471 comparison to Den3 IgG control group were calculated by Ordinary One-Way ANOVA test using 472 Graph Pad Prism 8.0. For weights and serum titers, error bars represent group average with 473 standard error of the mean. 


\section{SOM Tables}

475

476

\begin{tabular}{|c|c|c|c|c|}
\cline { 2 - 5 } \multicolumn{1}{c|}{} & H1 & H2 & H3 & Combinatorial \\
\cline { 2 - 5 } \multicolumn{1}{c|}{} & FITYWI & IIYPGDSE & GGSGISTPMDV & H1*H2*H3 \\
\hline NNK CDRs & 192 & 256 & 352 & $1.73 \mathrm{E}+07$ \\
\hline Rational CDRs & 107 & 142 & 196 & $2.98 \mathrm{E}+06$ \\
\hline
\end{tabular}

\begin{tabular}{|c|c|c|c|c|}
\cline { 2 - 5 } \multicolumn{1}{c|}{} & L1 & L2 & L3 & Combinatorial \\
\cline { 2 - 5 } \multicolumn{1}{c|}{} & VLYSSINKNYL & IYWASTRE & QQYYSTPY & L1*L2*L3 $^{*}{ }^{*}$ \\
\hline NNK CDRs & 352 & 256 & 256 & $2.31 \mathrm{E}+07$ \\
\hline Rational CDRs & 192 & 141 & 141 & $3.82 \mathrm{E}+06$ \\
\hline
\end{tabular}

478 Table S1. Theoretical library size. Related to Figure 1. Comparison of NNK generated libraries

479 to rationally synthesized CDR libraries. The sequence of the starting CDR loop is given along with

480 the number of variants in each loop that would result from NNK scanning or rational synthesis.

481 The combinatorial size of the CDR1/2/3 library is given from the product of the 3 loops. 
bioRxiv preprint doi: https://doi.org/10.1101/2021.05.29.443900; this version posted May 30, 2021. The copyright holder for this preprint (which was not certified by peer review) is the author/funder. All rights reserved. No reuse allowed without permission.

\begin{tabular}{|c|c|c|c|c|c|c|c|c|c|c|c|c|}
\hline \multirow{2}{*}{ mAb ID } & \multirow{2}{*}{ CDRH1 } & \multirow{2}{*}{ CDRH2 } & \multirow{2}{*}{ CDRH3 } & \multirow{2}{*}{ CDRL1 } & \multirow{2}{*}{ CDRL2 } & \multirow{2}{*}{ CDRL3 } & \multicolumn{3}{|c|}{ SPR against SARS-CoV-2 RBD } & \multicolumn{3}{|c|}{ SPR against SARS-CoV RBD } \\
\hline & & & & & & & $\mathrm{ka}[1 / \mathrm{Ms}]$ & $\mathrm{kd}[1 / \mathrm{s}]$ & $\mathrm{KD}[\mathrm{M}]$ & $\mathrm{ka}[1 / \mathrm{Ms}]$ & $\mathrm{kd}[1 / \mathrm{s}]$ & $\mathrm{KD}[\mathrm{M}]$ \\
\hline CR3022 & FITYWI & IIYPGDSE & GGSGISTPMDV & VLYSSINKNYL & IYWASTRE & QQYYSTPY & $1.26 \mathrm{E}+06$ & $3.31 \mathrm{E}-02$ & $2.62 \mathrm{E}-08$ & $1.36 \mathrm{E}+06$ & $2.84 \mathrm{E}-04$ & $2.10 \mathrm{E}-10$ \\
\hline eCR3022.1 & FIYYWI & IIYPGDGE & GGGGISTPMDV & VLWSSINKNYL & IYWASRRE & QQYYRTPY & $1.26 \mathrm{E}+06$ & $1.58 \mathrm{E}-04$ & $1.25 \mathrm{E}-10$ & $1.11 \mathrm{E}+06$ & $1.24 \mathrm{E}-04$ & $1.12 \mathrm{E}-10$ \\
\hline eCR3022.2 & FIWYWI & IIYPGDGE & GGGGISTPMDV & VLWSSINKNYL & IYWASQRE & QQYQSTPY & $1.93 \mathrm{E}+06$ & $1.43 \mathrm{E}-04$ & $7.41 \mathrm{E}-11$ & $1.37 \mathrm{E}+06$ & $4.13 \mathrm{E}-04$ & $3.02 \mathrm{E}-10$ \\
\hline eCR3022.3 & FIYYWI & IIYPGDEE & GGGGISTPMDV & VLWSSINKNYL & LYWASTRE & QQYRSTPY & $2.15 \mathrm{E}+06$ & $3.50 \mathrm{E}-05$ & $1.62 \mathrm{E}-11$ & $1.73 \mathrm{E}+06$ & $1.17 \mathrm{E}-04$ & $6.79 \mathrm{E}-11$ \\
\hline eCR3022.4 & FIYYWI & IIYPGDSE & GGGGISTPMDV & VLWSSINKNYL & IYWASYRE & EQYYSTPY & $1.12 \mathrm{E}+06$ & $1.19 \mathrm{E}-04$ & $1.07 \mathrm{E}-10$ & $1.02 \mathrm{E}+06$ & $1.14 \mathrm{E}+04$ & $1.12 \mathrm{E}-10$ \\
\hline eCR3022.5 & FIFYWI & IIYPGDGE & GGGGISTPMDV & VLWSSINKNYL & IYWGSTRE & NQYYSTPY & $1.82 \mathrm{E}+06$ & 1.17E-04 & $6.43 \mathrm{E}-11$ & $7.35 \mathrm{E}+05$ & $1.33 \mathrm{E}-04$ & $1.81 \mathrm{E}-10$ \\
\hline eCR3022.6 & FIFYWI & IIYPGDGE & GGGGISTPMDV & VLWSSINKNYL & EYWASTRE & QQYYSTPY & $2.03 \mathrm{E}+06$ & $1.04 \mathrm{E}-04$ & $5.13 \mathrm{E}-11$ & $8.12 \mathrm{E}+05$ & $1.57 \mathrm{E}-04$ & $1.94 \mathrm{E}-10$ \\
\hline eCR3022.7 & FIWYWI & IIYPGDGE & GGGGISTPMDV & VLWSSINKNYL & IYWASRRE & NQYYSTPY & $1.17 \mathrm{E}+06$ & $1.48 \mathrm{E}-04$ & 1.27E-10 & $9.39 \mathrm{E}+05$ & $1.69 \mathrm{E}-04$ & $1.80 \mathrm{E}-10$ \\
\hline eCR3022.8 & FIYYWI & IIYPGDGE & GGGGISTPMDV & VLWSSINKNYL & IYWASHRE & EQYYSTPY & $1.59 \mathrm{E}+06$ & $3.32 \mathrm{E}-05$ & $2.10 \mathrm{E}-11$ & $1.44 \mathrm{E}+06$ & $9.74 \mathrm{E}-05$ & $6.77 \mathrm{E}-11$ \\
\hline eCR3022.9 & FIYYWI & IIYPGDGE & GGGGISTPMDV & VLWSSINKNYL & IYWASKRE & QQYYITPY & $1.10 \mathrm{E}+06$ & $3.42 \mathrm{E}-04$ & $3.12 \mathrm{E}-10$ & $1.07 \mathrm{E}+06$ & $1.73 \mathrm{E}-04$ & $1.63 \mathrm{E}-10$ \\
\hline eCR3022.10 & FIYYWI & IIYPGDGE & GGGGISTPMDV & VLWSSINKNYL & IYWARTRE & QNYYSTPY & $1.52 \mathrm{E}+06$ & $1.68 \mathrm{E}-04$ & $1.10 \mathrm{E}-10$ & $1.32 \mathrm{E}+06$ & $1.78 \mathrm{E}-04$ & $1.35 \mathrm{E}-10$ \\
\hline eCR3022.11 & FIFYWI & IIYPGDGE & GGGGISTPMDV & VLWSSINKNYL & IYWAGTRE & AQYYSTPY & $2.18 \mathrm{E}+06$ & $6.86 \mathrm{E}-05$ & $3.14 \mathrm{E}-11$ & $9.67 \mathrm{E}+05$ & $9.35 \mathrm{E}-05$ & $9.67 \mathrm{E}-11$ \\
\hline eCR3022.12 & FIYYWI & IIYPGDGE & GGGGISTPMDV & VLYSSINKNYV & IYWASYRE & QQYYSHPY & $1.30 \mathrm{E}+06$ & $1.22 \mathrm{E}-04$ & $9.40 \mathrm{E}-11$ & $1.26 \mathrm{E}+06$ & 1.83E-04 & $1.45 \mathrm{E}-10$ \\
\hline eCR3022.13 & FIFYWI & IIYPGDGE & GGGGISTPMDV & VLWSSINKNYL & IYWESTRE & GQYYSTPY & $2.43 \mathrm{E}+06$ & 4.55E-05 & $1.87 \mathrm{E}-11$ & $9.55 \mathrm{E}+05$ & $7.40 \mathrm{E}-05$ & $7.75 \mathrm{E}-11$ \\
\hline eCR3022.14 & FIYYWI & IIYPGDGE & GGGGISTPMDV & VLWSSINKNYL & IYWASTQE & QQYKSTPY & $2.04 \mathrm{E}+06$ & $1.45 \mathrm{E}-04$ & $7.09 \mathrm{E}-11$ & $1.83 \mathrm{E}+06$ & $1.80 \mathrm{E}-04$ & $9.84 \mathrm{E}-11$ \\
\hline eCR3022.15 & FIYYWI & IIYPGDGE & GGGGISTPMDV & VLWSSINKNYL & IYWAQTRE & NQYYSTPY & $1.31 \mathrm{E}+06$ & $8.93 \mathrm{E}-05$ & $6.83 \mathrm{E}-11$ & $1.24 \mathrm{E}+06$ & $1.02 \mathrm{E}-04$ & $8.23 \mathrm{E}-11$ \\
\hline eCR3022.16 & FIFYWI & IIYPGDGE & GGGGISTPMDV & VLYSSWNKNYL & IYWALTRE & QQYKSTPY & $1.59 \mathrm{E}+06$ & $1.91 \mathrm{E}-04$ & $1.20 \mathrm{E}-10$ & $1.05 \mathrm{E}+06$ & $2.76 \mathrm{E}-04$ & $2.64 \mathrm{E}-10$ \\
\hline eCR3022.17 & FIWYWI & IIYPGDGE & GGGGISTPMDV & VLRSSINKNYL & IYWASHRE & QQYYSWPY & $1.59 \mathrm{E}+06$ & 1.07E-04 & $6.71 \mathrm{E}-11$ & $1.27 \mathrm{E}+06$ & $2.54 \mathrm{E}-04$ & $1.99 \mathrm{E}-10$ \\
\hline eCR3022.18 & FIFYWI & IIYPGDGE & GGGGISTPMDV & VLKSSINKNYL & IYWASARE & LQYYSTPY & $1.87 \mathrm{E}+06$ & $8.77 \mathrm{E}-05$ & $4.70 \mathrm{E}-11$ & $7.42 \mathrm{E}+05$ & $2.96 \mathrm{E}-04$ & $3.98 \mathrm{E}-10$ \\
\hline eCR3022.19 & FIYYWI & IIYPGDGE & GGGGISTPMDV & VLKSSINKNYL & IYWHSTRE & AQYYSTPY & $1.54 \mathrm{E}+06$ & $1.41 \mathrm{E}-04$ & $9.10 \mathrm{E}-11$ & $1.29 \mathrm{E}+06$ & $4.77 \mathrm{E}-04$ & $3.70 \mathrm{E}-10$ \\
\hline eCR3022.20 & FIWYWI & IIYPGDGE & GGGGISTPMDV & VLWSSINKNYL & IYWASTPE & QQYYKTPY & $1.85 \mathrm{E}+06$ & $7.93 \mathrm{E}-05$ & $4.28 \mathrm{E}-11$ & $1.55 \mathrm{E}+06$ & $1.11 \mathrm{E}-04$ & $7.14 \mathrm{E}-11$ \\
\hline eCR3022.21 & FIYYWI & IIYPGDEE & GGGGISTPMDV & VLRSSINKNYL & IYWASHRE & GQYYSTPY & $1.86 \mathrm{E}+06$ & $1.03 \mathrm{E}-04$ & $5.52 \mathrm{E}-11$ & $1.59 \mathrm{E}+06$ & $2.65 \mathrm{E}-04$ & $1.67 \mathrm{E}-10$ \\
\hline eCR3022.22 & FIYYWI & IIYPGDGE & GGGGISTPMDV & VLWSSINKNYL & IYWASHRE & QQYKSTPY & $1.86 \mathrm{E}+06$ & $1.35 \mathrm{E}-04$ & $7.28 \mathrm{E}-11$ & $1.63 \mathrm{E}+06$ & 1.87E-04 & $1.15 \mathrm{E}-10$ \\
\hline eCR3022.23 & FIYYWI & IIYPGDGE & GGGGISTPMDV & VLYHSINKNYL & IYWASHRE & QQYHSTPY & $2.03 \mathrm{E}+06$ & $1.18 \mathrm{E}-04$ & $5.82 \mathrm{E}-11$ & $9.49 \mathrm{E}+05$ & $3.46 \mathrm{E}-04$ & $3.65 \mathrm{E}-10$ \\
\hline eCR3022.24 & FIFYWI & IIYPGDGE & GGGGISTPMDV & VLWSSINKNYL & IYWKSTRE & QQYHSTPY & $1.76 \mathrm{E}+06$ & $1.09 \mathrm{E}-04$ & $6.19 \mathrm{E}-11$ & $7.55 \mathrm{E}+05$ & $1.31 \mathrm{E}-04$ & $1.74 \mathrm{E}-10$ \\
\hline eCR3022.25 & FIYYWI & IIYPGDSE & GGGGISTPMDV & VLWSSINKNYL & IYWSSTRE & EQYYSTPY & $1.59 \mathrm{E}+06$ & $7.66 \mathrm{E}-05$ & $4.81 \mathrm{E}-11$ & $1.37 \mathrm{E}+06$ & $1.11 \mathrm{E}-04$ & $8.15 \mathrm{E}-11$ \\
\hline
\end{tabular}

483 Table S2. eCR3022 binding affinity and CDR loop sequences. Related to Figure 2. Summary

484 table of parental CR3022 and 25 eCR3022 antibodies with sequences of 6 CDR loops and binding 485 affinity against SARS-CoV-2 RBD and SARS-CoV-1 RBD. Mutations of eCR3022 at CDR loops 486 were highlighted in red. Antibodies were captured via Fc-capture to an anti-human IgG FC 487 antibody and varying concentrations of SARS-CoV-2 or SARS-CoV-1 RBD were injected using a 488 multi-cycle method. Association and dissociation rate constants calculated through a 1:1 489 Langmuir binding model using the BIAevaluation software. 


\begin{tabular}{|c|c|}
\hline Data collection & $\begin{array}{l}\text { eCR3022.20 + SARS-CoV-2 RBD } \\
+ \text { CC12.3 }\end{array}$ \\
\hline Beamline & SSRL12-1 \\
\hline Wavelength $(\AA)$ & $0.97946 \AA$ \\
\hline Space group & C 2221 \\
\hline \multicolumn{2}{|l|}{ Unit cell parameters } \\
\hline$a, b, c(\AA)$ & $157.6,161.2,230.1$ \\
\hline$\alpha, \beta, \gamma\left({ }^{\circ}\right)$ & $90,90,90$ \\
\hline Resolution $(\AA)^{a}$ & $50.0-2.85(2.90-2.85)$ \\
\hline Unique reflections $^{a}$ & 67,884 \\
\hline Redundancy ${ }^{a}$ & $3.3(3.3)$ \\
\hline Completeness (\%) ${ }^{a}$ & $99.4(99.9)$ \\
\hline$<1 / \sigma_{1}>a$ & $24.6(1.1)$ \\
\hline$R_{\mathrm{sym}}{ }^{\mathrm{b}}(\%)^{\mathrm{a}}$ & $14.5(>100)$ \\
\hline$R_{\text {pim }}^{\mathrm{b}}(\%)^{\mathrm{a}}$ & $6.2(45.2)$ \\
\hline $\mathrm{CC}_{1 / 2}^{\mathrm{c}}(\%)^{\mathrm{a}}$ & $98.4(66.0)$ \\
\hline \multicolumn{2}{|l|}{ Refinement statistics } \\
\hline Resolution $(\AA)$ & $2.90-2.85$ \\
\hline Reflections (work) & 67,847 \\
\hline Reflections (test) & 3,440 \\
\hline$R_{\text {cryst }}{ }^{\mathrm{d}} / R_{\text {free }} \mathrm{e}(\%)$ & $20.9 / 25.1$ \\
\hline No. of atoms & 16,286 \\
\hline Macromolecules & 16,244 \\
\hline RBD & 3,066 \\
\hline eCR3022.20 Fab & 6,676 \\
\hline $\mathrm{CC} 12.3 \mathrm{Fab}$ & 6,502 \\
\hline Glycan & 42 \\
\hline Average $B$-values $\left(\AA^{2}\right)$ & 60 \\
\hline Macromolecules & 60 \\
\hline $\mathrm{RBD}$ & 63 \\
\hline eCR3022.20 Fab & 57 \\
\hline $\mathrm{CC} 12.3 \mathrm{Fab}$ & 62 \\
\hline Glycan & 85 \\
\hline Wilson $B$-value $\left(\AA^{2}\right)$ & 61 \\
\hline
\end{tabular}

RMSD from ideal geometry

Bond length $(\AA) \quad 0.005$

Bond angle $\left({ }^{\circ}\right) \quad 1.2$

Ramachandran statistics (\%)

Favored 95.6

Outliers $\quad 0.24$

PDB code pending

${ }^{a}$ Numbers in parentheses refer to the highest resolution shell.

${ }^{\mathrm{b}} R_{\text {sym }}=\Sigma_{h k l} \Sigma_{i}\left|I_{h k, i}-<I_{h k l}>\right| / \Sigma_{h k l} \Sigma_{i} I_{h k, i}$ and $R_{p i m}=\Sigma_{h k l}(1 /(n-1))^{1 / 2} \Sigma_{i}\left|I_{h k l, i}-<I_{h k l}>\right| / \Sigma_{h k l} \Sigma_{i} I_{h k l, i}$, where $I_{h k l, i}$ is the scaled intensity of the

$\mathrm{i}^{\text {th }}$ measurement of reflection $\mathrm{h}, \mathrm{k}, \mathrm{l}, \mathrm{l}_{h k \mathrm{l}}>$ is the average intensity for that reflection, and $n$ is the redundancy.

${ }^{\mathrm{c}} \mathrm{CC}_{1 / 2}=$ Pearson correlation coefficient between two random half datasets.

${ }^{d} R_{\text {cryst }}=\Sigma_{h k l}\left|F_{\mathrm{o}}-F_{\mathrm{c}}\right| / \Sigma_{h k l}\left|F_{\mathrm{o}}\right| \times 100$, where $F_{\mathrm{o}}$ and $F_{\mathrm{c}}$ are the observed and calculated structure factors, respectively.

${ }^{\text {e }} R_{\text {free }}$ was calculated as for $R_{\text {cryst }}$, but on a test set comprising $5 \%$ of the data excluded from refinement. 


\begin{tabular}{|c|c|c|c|c|c|c|c|c|c|c|c|c|c|c|}
\hline Animal ID & Antibody & Dose (mg) & $\begin{array}{c}\text { Weight (g) at D- } \\
3\end{array}$ & $\begin{array}{c}\text { Weight (g) at } \\
\text { DO }\end{array}$ & $\begin{array}{c}\text { Weight (g) at } \\
\text { D1 }\end{array}$ & $\begin{array}{c}\text { Weight (g) at } \\
\text { D2 }\end{array}$ & $\begin{array}{c}\text { Weight (g) at } \\
D 3\end{array}$ & $\begin{array}{c}\text { Weight (g) at } \\
D 4\end{array}$ & $\begin{array}{c}\text { Weight (g) at } \\
\text { D5 }\end{array}$ & $\begin{array}{c}\text { Weight (g) at } \\
\text { D6 }\end{array}$ & $\begin{array}{c}\text { Weight (g) at } \\
\text { D7 }\end{array}$ & $\begin{array}{l}\text { Serum titer at } \\
\text { Day } 0(\mu \mathrm{g} / \mathrm{mL})\end{array}$ & $\begin{array}{l}\text { Serum titer at } \\
\text { Day } 7(\mu \mathrm{g} / \mathrm{mL})\end{array}$ & $\begin{array}{c}\text { Sars-CoV-2 } \\
\text { PFU } / \mathrm{mL} \text { at D4 }\end{array}$ \\
\hline 2371 & Den3 Ctrl & 10 & 140.7 & 142.4 & 140.7 & 139.8 & 136.5 & 124.5 & 133 & 132.4 & 132 & 0 & 0 & $3.00 \mathrm{E}+05$ \\
\hline 2372 & Den3 Ctrl & 10 & 169.4 & 173.3 & 172.1 & 169.1 & 167.3 & 163.6 & 159.4 & 158.1 & 157 & 0 & 0 & $9.00 E+05$ \\
\hline 2373 & Den3 $\mathrm{Ctrl}$ & 10 & 127.4 & 128.8 & 126.8 & 124.9 & 122.2 & 121 & 118.5 & 117.7 & 116.3 & 0 & 0 & $9.00 E+06$ \\
\hline 2374 & Den3 Ctrl & 10 & 140.3 & 143.6 & 141.2 & 137.5 & 134.9 & 130.7 & 127.3 & 123.5 & 119.9 & 0 & 0 & $1.50 \mathrm{E}+08$ \\
\hline 2375 & Den3 Ctrl & 10 & 145.7 & 147.9 & 146.2 & 143.2 & 140.1 & 137.3 & 135.7 & 135.7 & 135.2 & 0 & 0 & $1.05 E+07$ \\
\hline 2393 & Den3 Ctrl & 10 & 146.5 & 147.2 & 146.3 & 143.3 & 141 & 136.5 & 133.2 & 131.3 & 130.6 & 0 & 0 & $1.05 E+06$ \\
\hline 2366 & CR3022 & 10 & 166.2 & 167.4 & 166.2 & 162.6 & 158 & 153.2 & 149.7 & 146.6 & 142.4 & 643.28 & 224.49 & $4.50 E+05$ \\
\hline 2367 & CR3022 & 10 & 161.9 & 164.6 & 163.2 & 159.1 & 155.6 & 150.1 & 146.4 & 146.1 & 145.7 & 707.05 & 115.54 & $7.50 E+05$ \\
\hline 2368 & CR3022 & 10 & 147.7 & 150.9 & 149.1 & 146.5 & 145.4 & 141.1 & 143.2 & 143.2 & 145.4 & 260.46 & 136.43 & 4.50E+06 \\
\hline 2369 & CR3022 & 10 & 150 & 153.4 & 151.6 & 147.9 & 144.1 & 141.3 & 136.8 & 131.5 & 129.3 & 569.90 & 102.19 & $1.80 \mathrm{E}+05$ \\
\hline 2370 & CR3022 & 10 & 158.8 & 162.1 & 161.1 & 158.9 & 153.2 & 151.3 & 146.3 & 142 & 137.3 & 467.18 & 109.73 & $6.00 E+05$ \\
\hline 2392 & CR3022 & 10 & 156.6 & 158.4 & 156.2 & 151.9 & 147.2 & 144.9 & 139.9 & 140 & 143.1 & 558.62 & 283.71 & $6.00 E+05$ \\
\hline One Way & P-Value & 10 & 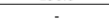 & & 0.9382 & 0.9898 & 0.8119 & 0.9999 & 0.9006 & 0.8517 & 0.9707 & $<0.0001$ & $<0.0001$ & 0.2215 \\
\hline ANOVA & Significance & 10 & - & - & ns & ns & ns & ns & ns & ns & ns & $* * * *$ & $: * * * *$ & ns \\
\hline 2361 & CR3022.7 & 10 & $\begin{array}{ll}149.4 \\
\end{array}$ & 153.2 & 152 & 148.1 & 148 & $\begin{array}{ll}151.8 \\
\end{array}$ & 154.1 & 155 & 155.7 & 603.78 & 242.27 & $1.20 E+05$ \\
\hline 2362 & CR3022.7 & 10 & 153.6 & 160.3 & 158.1 & 154.1 & 155.2 & 157.4 & 158.1 & 158.5 & 159.3 & 714.39 & 356.63 & $1.05 E+03$ \\
\hline 2363 & CR3022.7 & 10 & 165.9 & 171.3 & 169.9 & 166.6 & 167.2 & 169.3 & 171.1 & 172.2 & 173 & 569.76 & 202.71 & $6.00 \mathrm{E}+03$ \\
\hline 2364 & CR3022.7 & 10 & 155.1 & 155.8 & 153.2 & 149.2 & 148.8 & 150 & 151.6 & 153.2 & 157.6 & 438.53 & 112.24 & $3.00 E+03$ \\
\hline 2365 & CR3022.7 & 10 & 124.8 & 126.1 & 124.7 & 122.1 & 122.8 & 123.1 & 123.8 & 124.5 & 127.7 & 740.11 & 346.24 & $1.80 \mathrm{E}+03$ \\
\hline 2391 & CR 3022.7 & 10 & 155.3 & 153.2 & 151.8 & 148.3 & 147.9 & 149.4 & 152.8 & 154.2 & 157.2 & 419.67 & 140.24 & $3.00 \mathrm{E}+04$ \\
\hline One Way & P-Value & 10 & $\cdot$ & - & 0.9998 & 0.7868 & 0.3677 & 0.0002 & 0.0002 & $<0.0001$ & 0.0001 & $<0.0001$ & $<0.0001$ & $<0.0001$ \\
\hline ANOVA & Significance & 10 & - & - & ns & ns & ns & $* * *$ & $* * *$ & $* * * *$ & $* * *$ & $* * * *$ & $* * * *$ & $* * * *$ \\
\hline 2376 & $\begin{array}{l}\text { CR3022.7 } \\
\end{array}$ & 2 & 145.6 & 149.5 & 147 & 141.5 & 138.2 & 137.4 & 135.4 & 137.4 & 139.7 & 196.44 & 88.08 & $4.50 E+03$ \\
\hline 2377 & CR3022.7 & 2 & 157.1 & 158.8 & 156.8 & 155.2 & 155 & 155.4 & 156.5 & 157.2 & 159.4 & 246.33 & 89.47 & 4.50E+04 \\
\hline 2378 & СR3022.7 & 2 & 165.5 & 170.4 & 169 & 166 & 164.7 & 163.6 & 161.2 & 164.3 & 166.6 & 290.20 & 56.63 & $2.40 \mathrm{E}+04$ \\
\hline 2379 & CR3022.7 & 2 & 154.2 & 157 & 155.7 & 153.3 & 152.1 & 148.9 & 147.3 & 148.8 & 152.2 & 269.80 & 82.26 & $1.05 E+05$ \\
\hline 2380 & CR3022.7 & 2 & 164.5 & 167 & 165.2 & 160.8 & 157.4 & 156.8 & 152.8 & 153.8 & 155.4 & 202.87 & 40.37 & $1.95 E+03$ \\
\hline 2394 & CR3022.7 & 2 & 166.8 & 169.7 & 167.4 & 163.8 & 161.8 & 160 & 158.6 & 159.9 & 171.3 & 223.26 & 138.41 & $4.50 E+02$ \\
\hline One Way & P-Value & 2 & - & - & 0.9999 & 0.9172 & 0.9986 & 0.1091 & 0.4263 & 0.0976 & 0.0136 & 0.0002 & 0.0483 & $<0.0001$ \\
\hline ANOVA & Significance & 2 & . & & ns & ns & ns & ns & ns & ns & ${ }_{*}^{*}$ & ${ }_{* * *}^{* *+}$ & ${ }_{*}^{*}$ & $+*+*+$ \\
\hline 2386 & CR3022.7 & 0.5 & 153 & 162.7 & 160.1 & 153.3 & 153.8 & 155 & 154.9 & 156.4 & 162.5 & 26.02 & 7.96 & $3.00 \mathrm{E}+05$ \\
\hline 2387 & CR3022.7 & 0.5 & 155 & 158.3 & 156.4 & 153.4 & 153.2 & 153.5 & 149.8 & 151.4 & 153 & 22.57 & 0.62 & $4.50 E+05$ \\
\hline 2388 & CR3022.7 & 0.5 & 145 & 148.3 & 146.5 & 141.6 & 138 & 133.9 & 128.7 & 128.1 & 129.7 & 28.89 & 0.24 & $9.00 \mathrm{E}+04$ \\
\hline 2389 & CR3022.7 & 0.5 & 141.2 & 142.4 & 140.3 & 135.4 & 130.4 & 131.2 & 126.6 & 127.2 & 129.5 & 28.74 & 0.32 & $1.80 \mathrm{E}+06$ \\
\hline 2390 & CR3022.7 & 0.5 & 169.3 & 173.5 & 170.5 & 162.7 & 158 & 156.7 & 150.9 & 150 & 147.7 & 23.16 & 0.58 & $4.50 \mathrm{E}+05$ \\
\hline 2388 & CR 3022.7 & 0.5 & 140.5 & 144.9 & 143 & 138.3 & 134.9 & 134 & 133.2 & 131.1 & 132 & 31.03 & 3.05 & 1.35E+05 \\
\hline One Way & P-Value & 0.5 & $\cdot$ & $\cdot$ & 0.634 & 0.005 & 0.1445 & 0.9265 & 0.9927 & 0.9997 & 0.7831 & 0.9751 & $>0.9999$ & 0.0453 \\
\hline ANOVA & Significance & 0.5 & . & - & ns & $* *$ & ns & ns & ns & $\mathrm{ns}$ & $\mathrm{ns}$ & ns & ns & * \\
\hline 2381 & CR3022.7 & 0.125 & 148.2 & 151.7 & 149.5 & 144.9 & 143.2 & 144.1 & 144.6 & 145.5 & 147.7 & 8.80 & 0.62 & $4.50 \mathrm{E}+05$ \\
\hline 2382 & CR3022.7 & 0.125 & 147.8 & 128.3 & 128 & 126 & 125.5 & 123.4 & 124.3 & 124.9 & 125.2 & 7.84 & 0.00 & $9.00 E+05$ \\
\hline 2383 & CR3022.7 & 0.125 & 126.3 & 123.7 & 121.1 & 118.5 & 114.7 & 111.1 & 109.4 & 108 & 106.4 & 9.70 & 1.80 & $7.50 E+05$ \\
\hline 2384 & CR3022.7 & 0.125 & 149.9 & 150.9 & 148.5 & 143.3 & 140 & 138.2 & 135.1 & 135.7 & 136.2 & 9.00 & 0.00 & $1.65 \mathrm{E}+05$ \\
\hline 2385 & CR3022.7 & 0.125 & 148.2 & 151.9 & 149.5 & 145.7 & 142.2 & 141.6 & 140.8 & 141.2 & 141.3 & 10.31 & 1.70 & $3.00 E+05$ \\
\hline 2395 & CR3022.7 & 0.125 & 171.9 & 178.8 & 176.3 & 171.8 & 166 & 163.3 & 159.6 & 157.3 & 155.7 & 6.40 & 0.00 & $6.00 E+05$ \\
\hline One Way & P-Value & 0.125 & $\cdot$ & - & 0.7209 & 0.2344 & 0.5024 & 0.943 & 0.9927 & 0.8852 & 0.7756 & 0.9997 & $>0.9999$ & 0.0961 \\
\hline ANOVA & Significance & 0.125 & & & ns & ns & ns & ns & ns & ns & ns & $\mathrm{ns}$ & ns & ns \\
\hline
\end{tabular}




\section{SOM Figures}

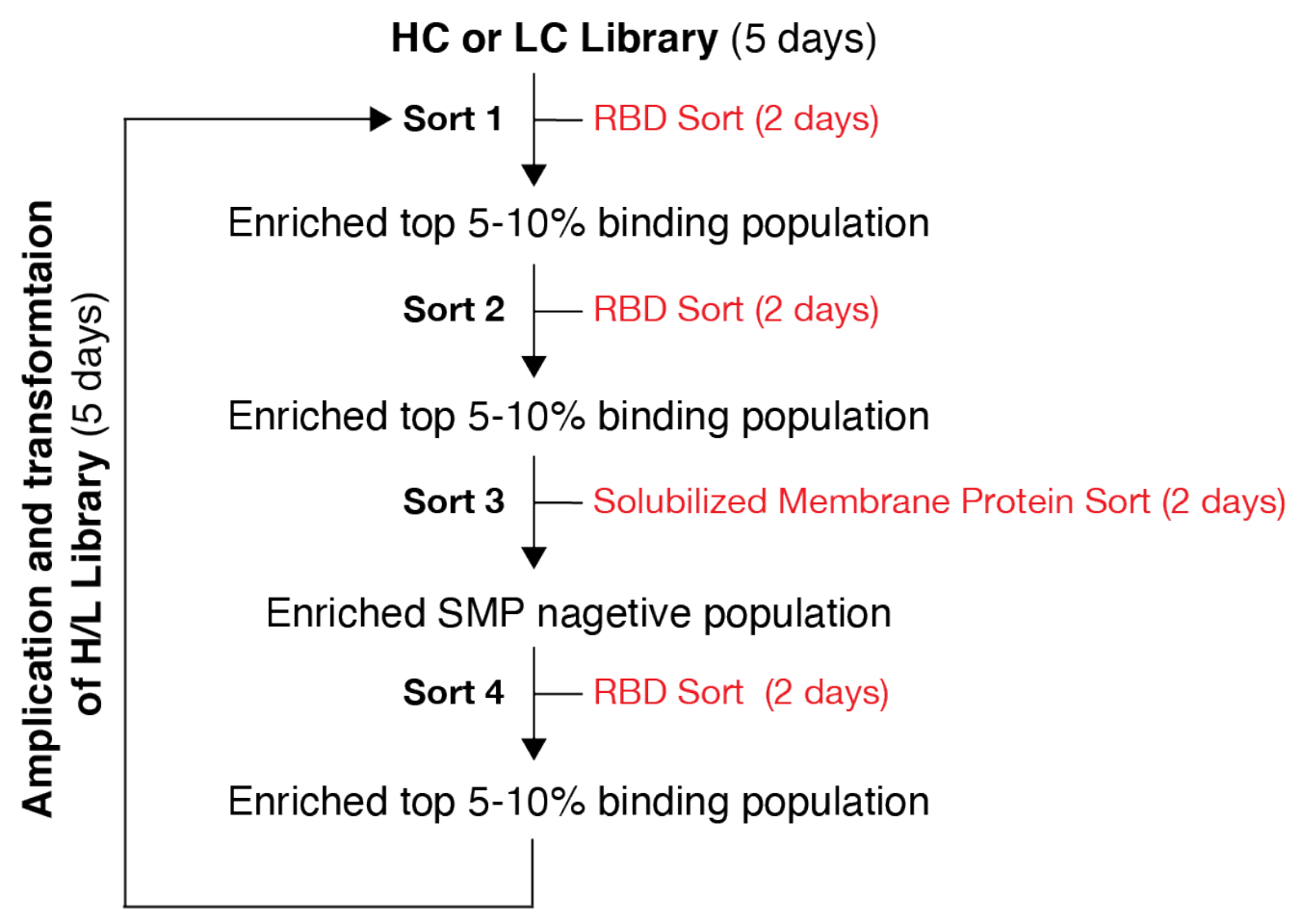

504 Figure S1. Overview of the library sorting process. Related to Figure 1. Schematic illustration 505 of yeast population enrichment from HC, LC and combinatorial $\mathrm{H} / \mathrm{L}$ libraries following four rounds 506 of FACS selection. 

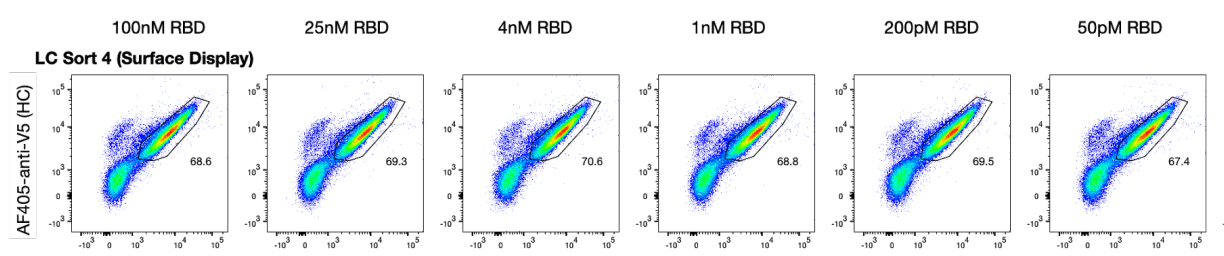

10pM RBD
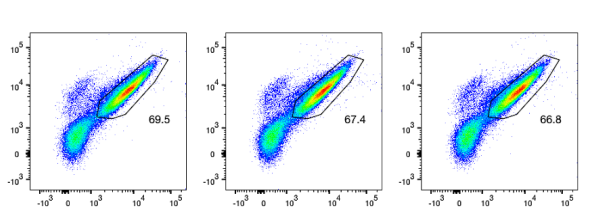

No RBD
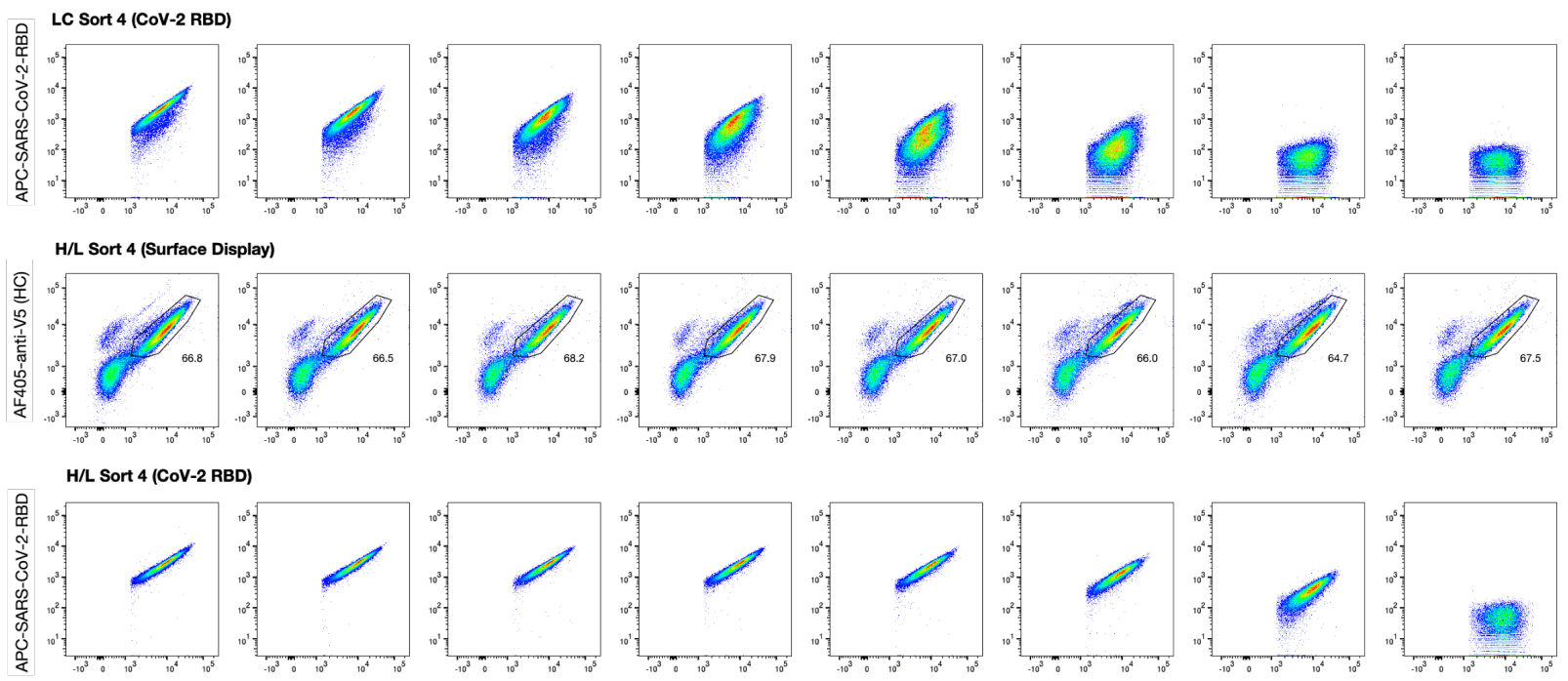

509 Figure S2. Representative FACS plots of CR3022 LC and H/L libraries in sort 4. Related to

510 Figure 1. Yeast cells were induced and grown overnight at $30^{\circ} \mathrm{C}$. Surface antibody display

511 frequency was determined by staining with AF405-anti-V5 antibody (HC) and FITC-anti-c-Myc

512 (LC). Cells were also labeled with different unsaturated concentrations of biotinylated SARS-CoV-

5132 RBD: 100 nM, 25 nM, 4 nM, 1 nM, 200 pM, 50 pM, 10 pM respectively. Labeled cells were

514 further stained with APC conjugated streptavidin. FACS analysis was performed by BD 515 FACSlyrics. 
CR3022 H/L Library
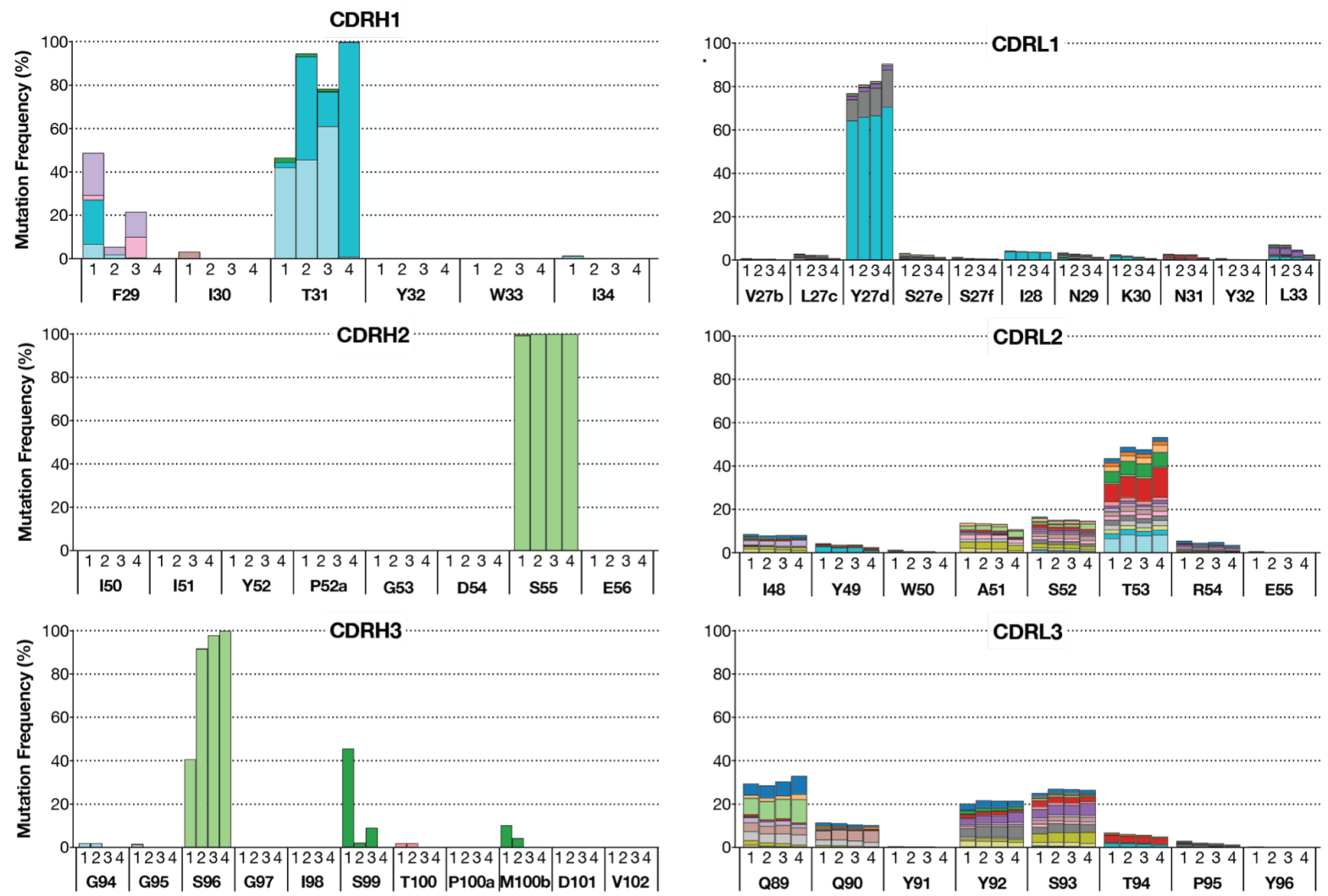

$\square \mathrm{A} \square \mathrm{C} \square \mathrm{D} \square \mathrm{E} \square \mathrm{F} \square \mathrm{G} \square \mathrm{H} \square \mathrm{I} \square \mathrm{K} \square \mathrm{L} \square \mathrm{M} \square \mathrm{N} \square \mathrm{P} \square \mathrm{Q} \square \mathrm{R} \square \mathrm{S} \square \mathrm{T} \square \mathrm{V} \square \mathrm{W} \square \mathrm{Y}$

517 Figure S3. Deep sequencing analysis of mutations of CDR loops from the CR3022

518 combinatorial H/L library. Related to Figure 1. HC and LC from the combinatorial H/L library

519 were amplified separately and then loaded onto Illumina Miseq sequencer using a Miseq Reagent

520 V3 kit (600 cycles). Mutations in each CDR loop of HC (left) and LC (right) after each round of

521 FACS sort were highlighted in colors corresponding to the key. 


\section{SARS-CoV-1S}

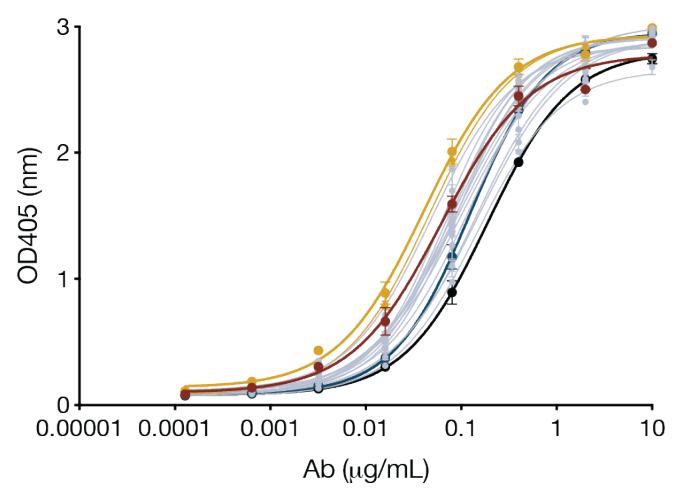

SARS-CoV-1 RBD

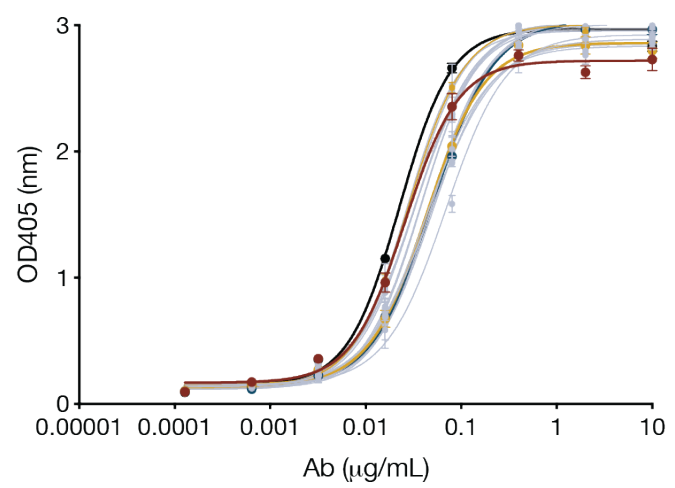

SARS-CoV-2 S

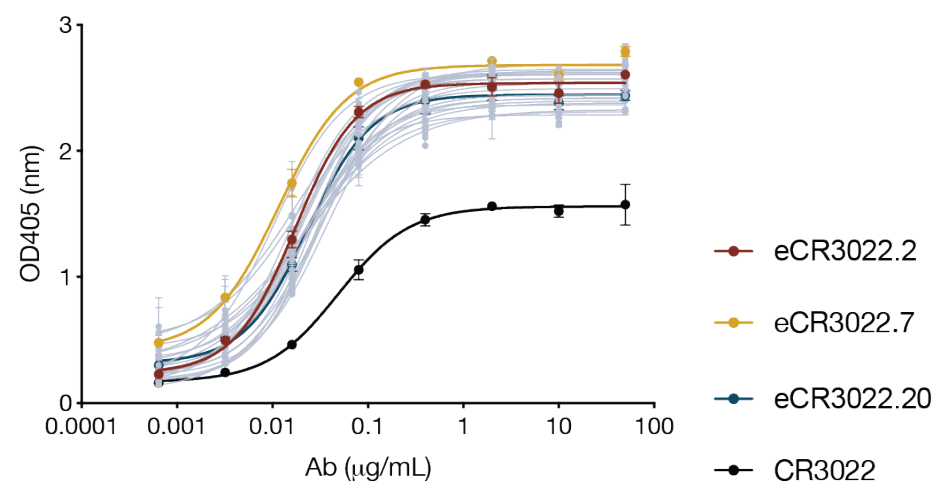

SARS-CoV-2 RBD

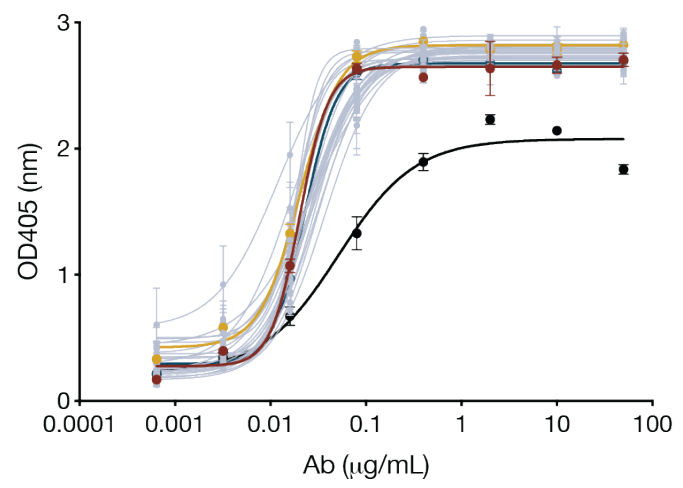

524 Figure S4. eCR3022 variants ELISA binding to SARS-CoV-1 and SARS-CoV-2 RBD and S 525 proteins. Related to Figure 2. eCR3022 and parental CR3022 antibodies were evaluated 526 binding against his-tagged SARS-CoV-1, SARS-CoV-2 RBD and S proteins. Each sample was 527 tested in duplicates. Error bars represent standard deviations. 

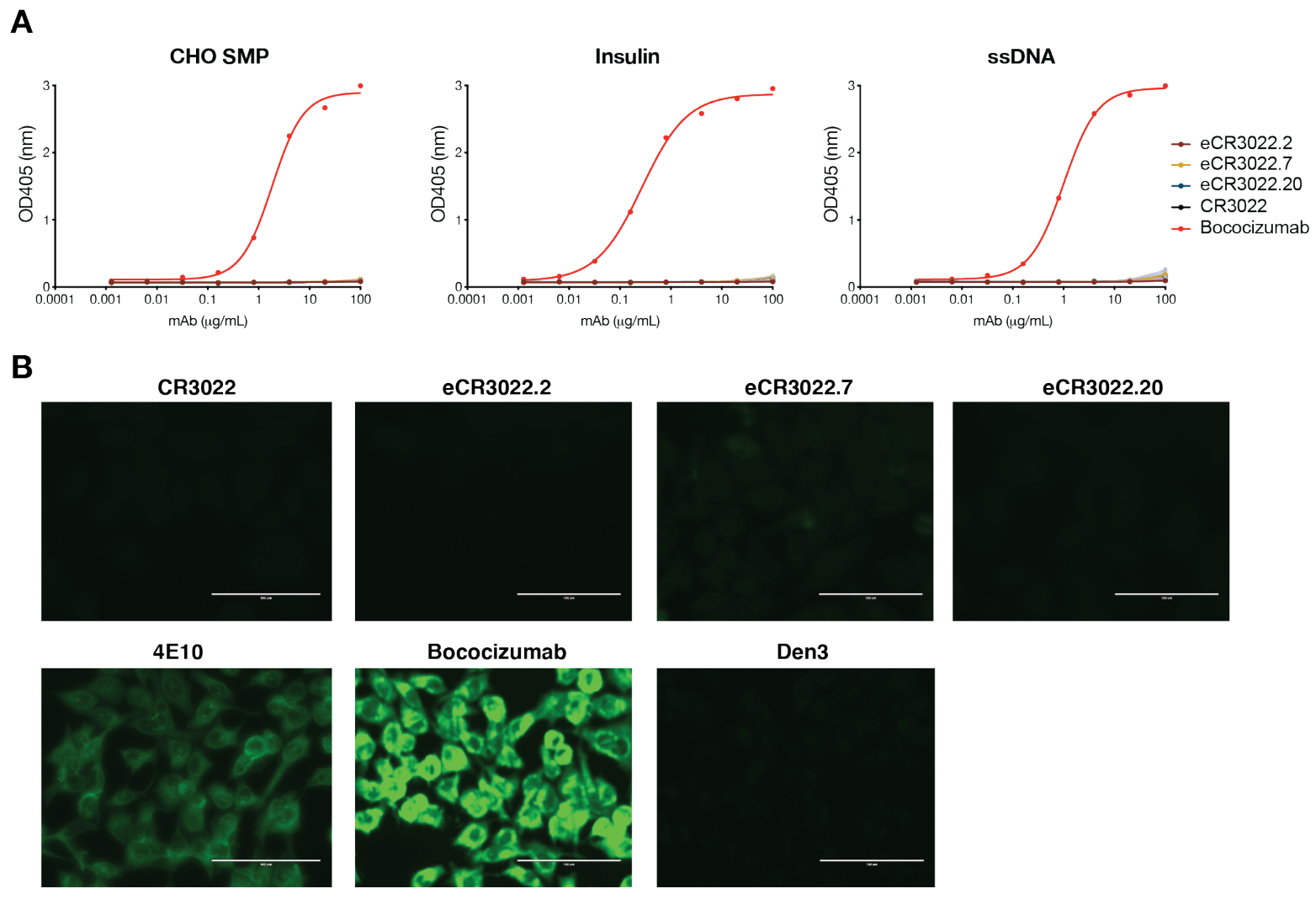

C
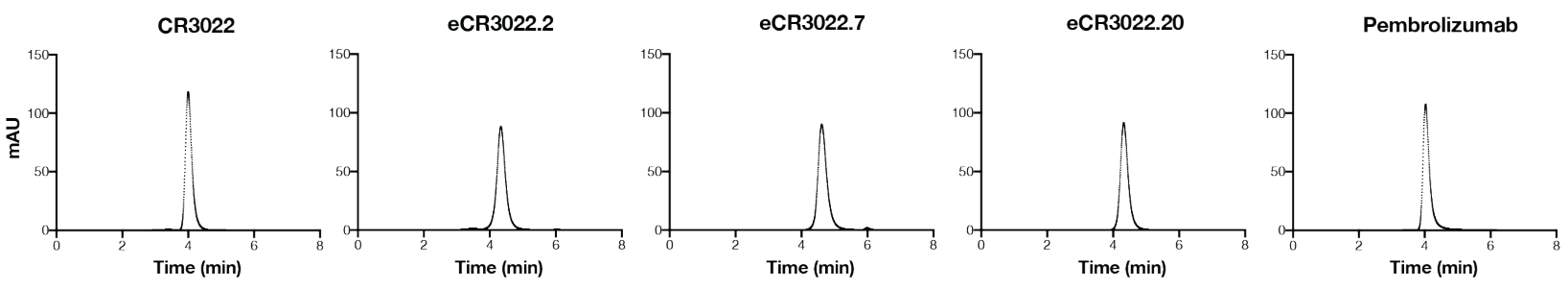

530 Figure S5. Evaluation of eCR3022 variants for polyreactivity and biopharmaceutical

531 analysis. Related to Figure 2. Antibodies were tested by ELISA for binding against polyspecific 532 reagents (PSR) against Chinese hamster ovary cells (CHO) solubilized membrane protein (SMP), 533 insulin, single-strand DNA (ssDNA) (A) and by binding to immobilized HEp2 epithelial cells (B).

534 Antibodies were further analyzed by Agilent size-exclusion chromatography (SEC) column (C) 535 with an FDA-approved antibody Pembrolizumab as positive control. 
B.1.1.7

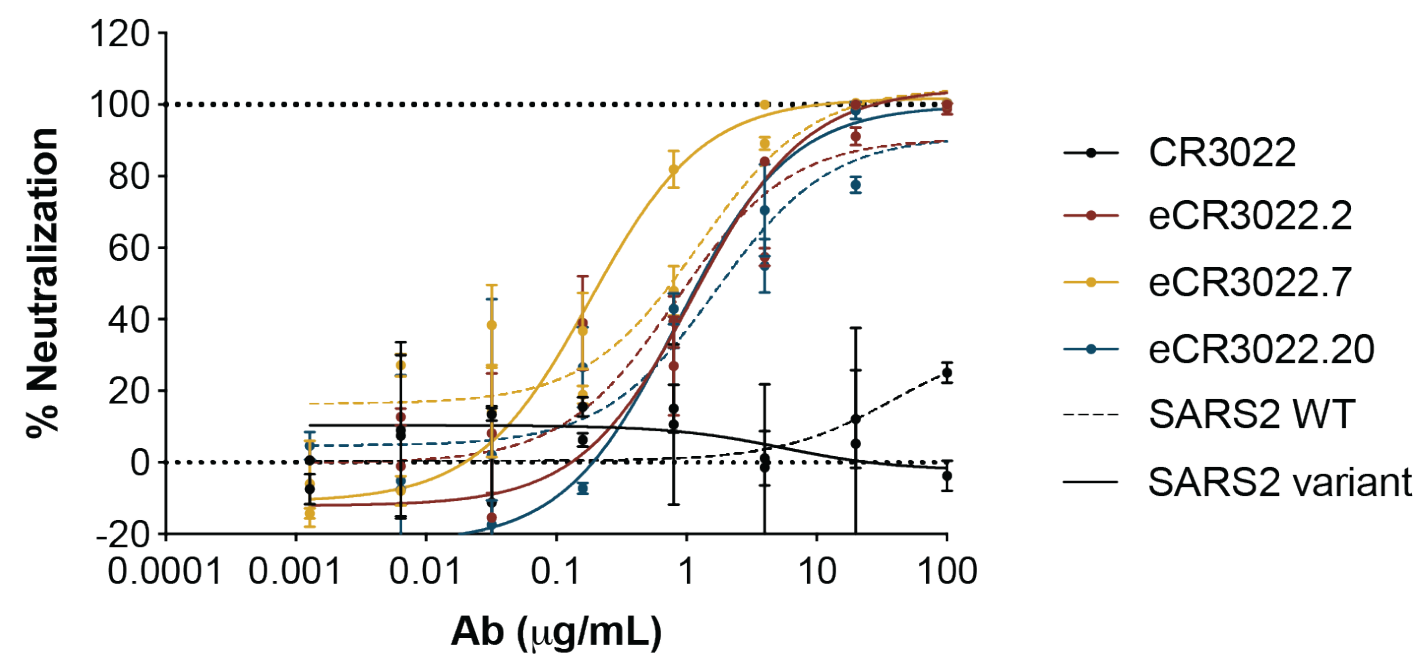

\section{B.1.351}

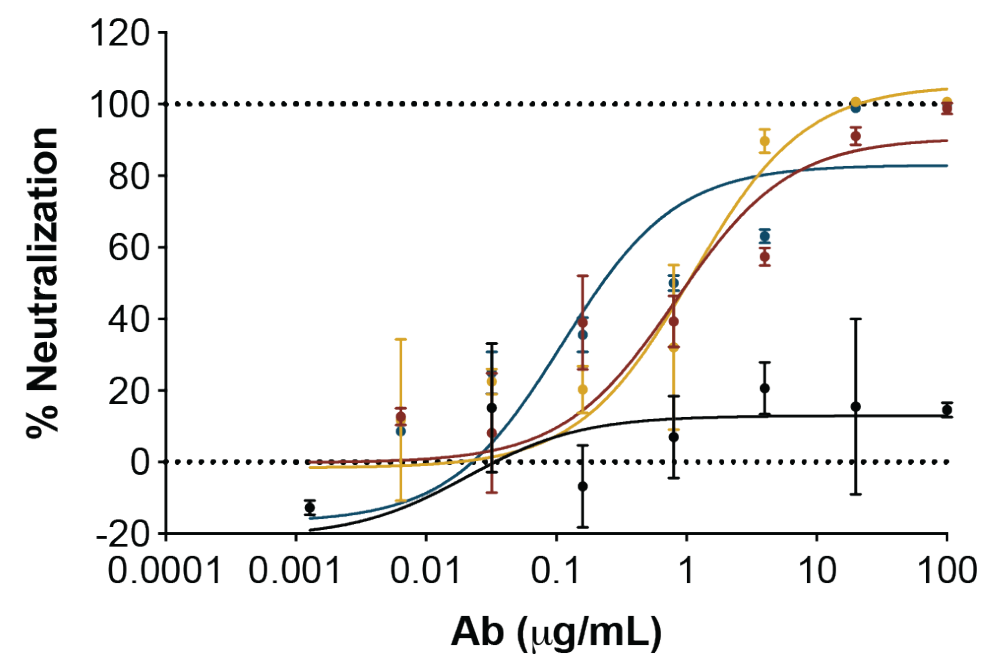

538 Figure S6. Representative neutralization of pseudotyped B.1.1.7 and B.1.351 variants.

539 Related to Figure 2. Neutralization curves of parental CR3022 and eCR3022 antibodies against

540 pseudotyped B.1.1.7 and B.1.351 lineages with full-spike mutations. Solid lines represent 541 neutralization curves against SARS-CoV-2 variants while dashed lines represent curves against 542 wildtype virus. Error bars represent standard deviations. 


\section{Authentic SARS-CoV-2}

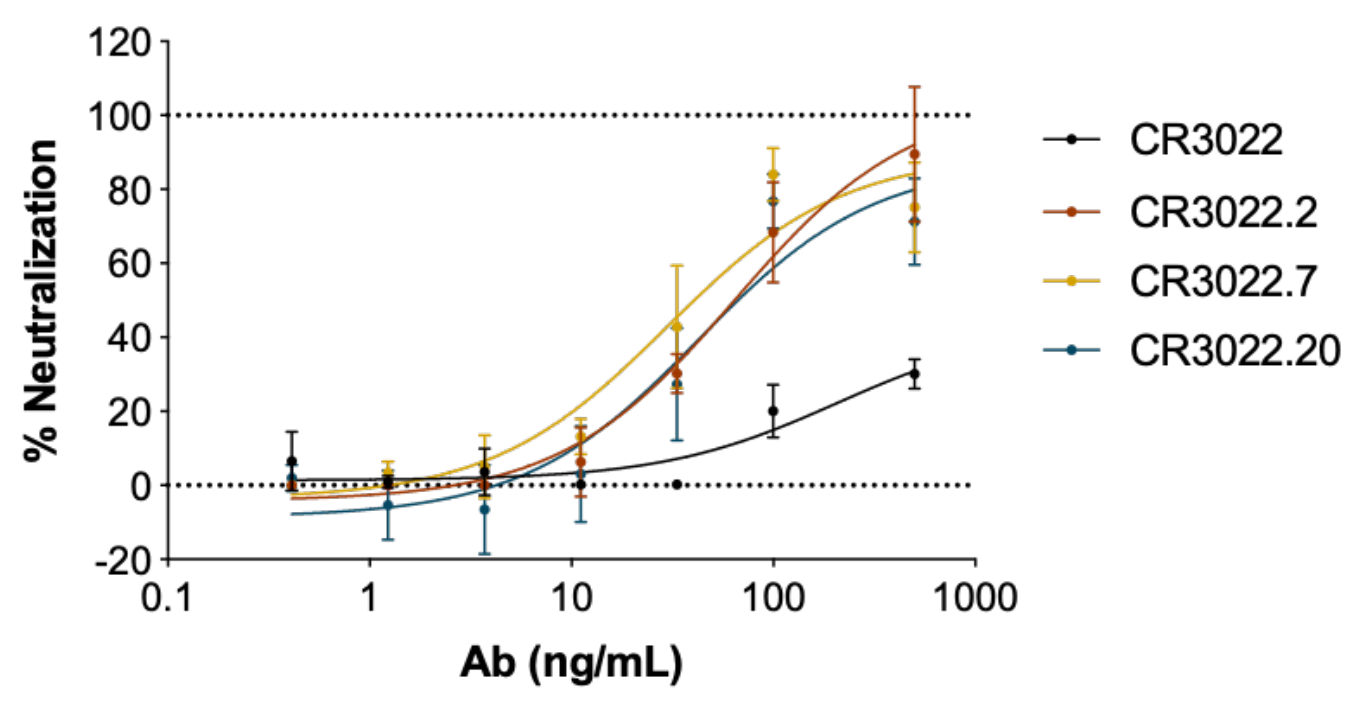

544 Figure S7. Representative neutralization of authentic SARS-CoV-2. Related to Figure 2.

545 Neutralization curves of parental CR3022 and eCR3022 antibodies against authentic SARS-CoV-

5462 (USA-WA1/2020). Each sample was tested in duplicates. Error bars represent standard 547 deviations. 


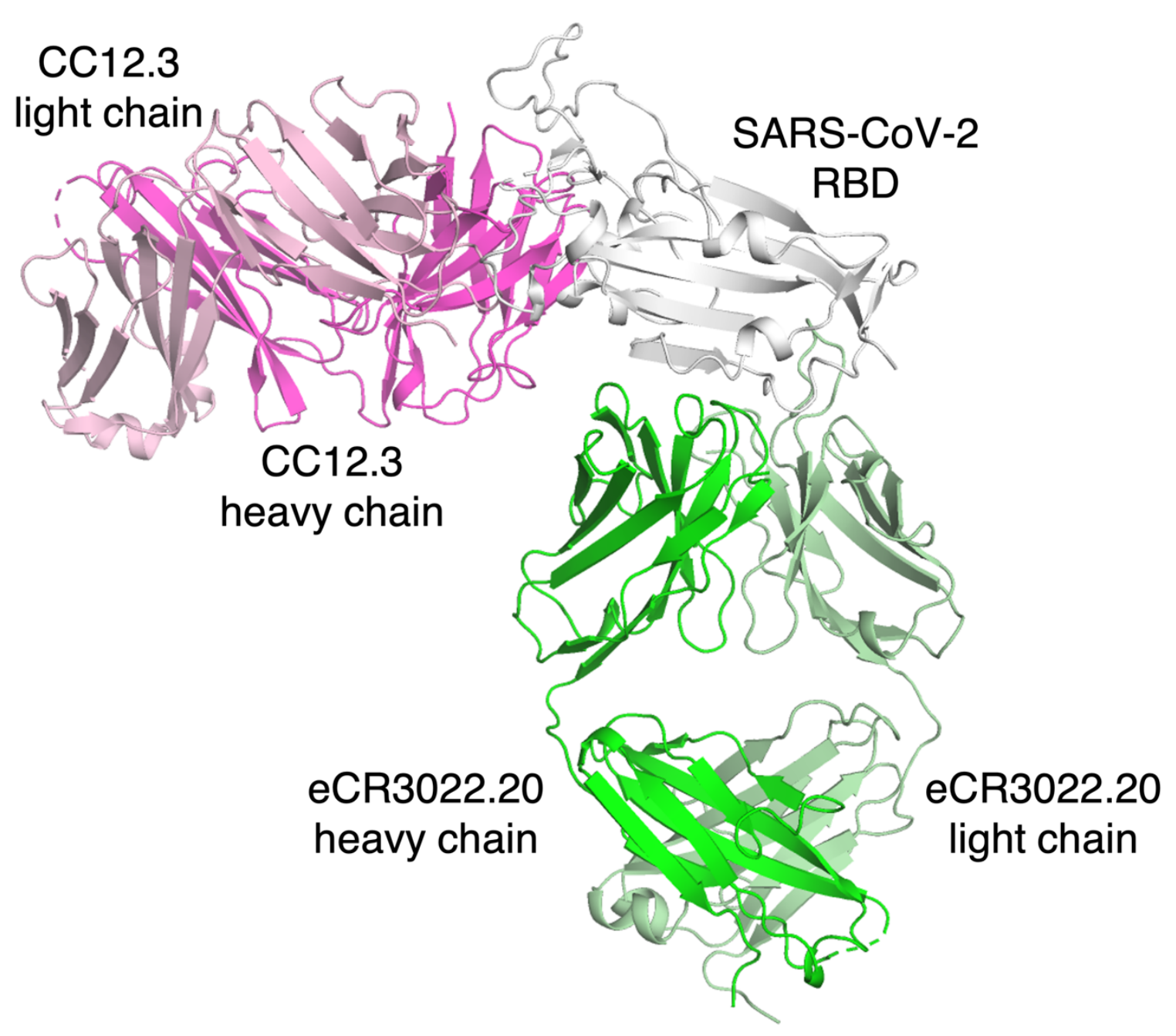
CC12.3. Related to Figure 3. The binding site of eCR3022.20 (Fab heavy and light chains shown

552 in green and light green, respectively) on the RBD (white) is distinct from that of CC12.3 (Fab 553 heavy and light chains shown in magenta and light pink, respectively), which binds to the receptor 554 binding site. 
A

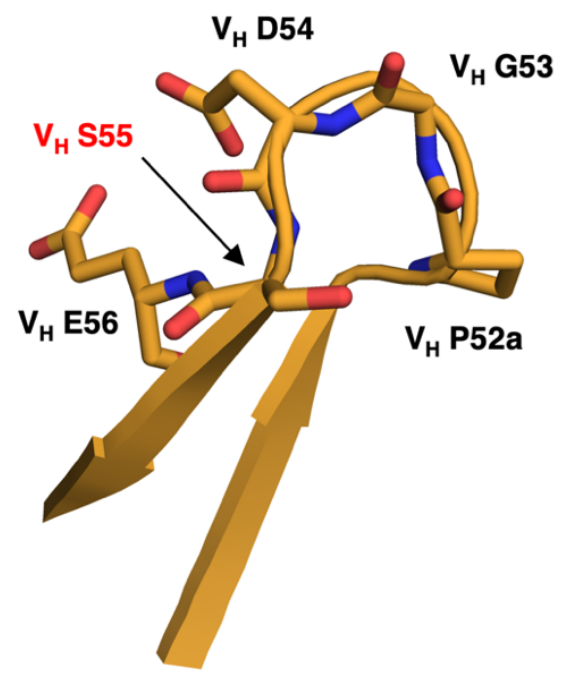

C

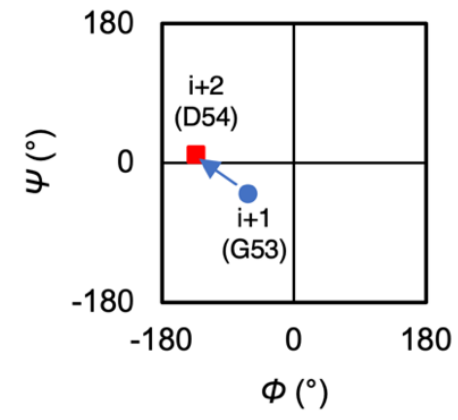

B

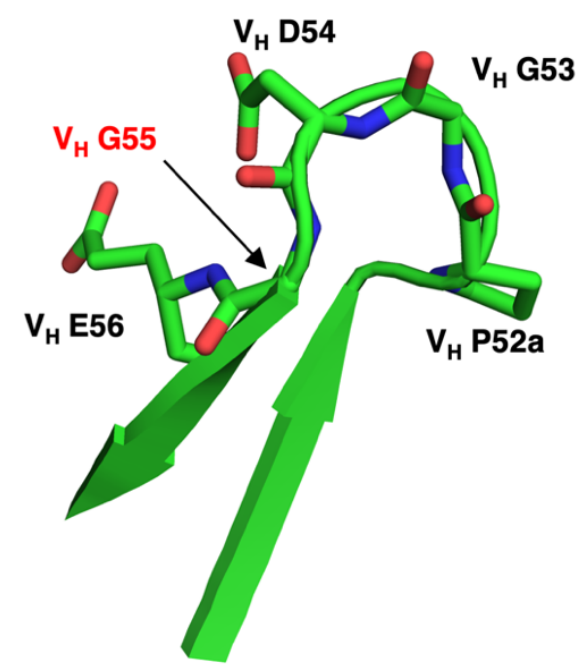

Type IV

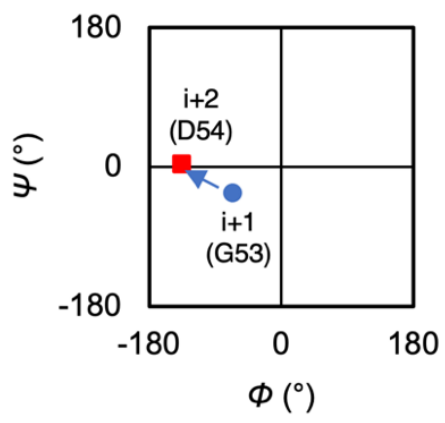

E

\begin{tabular}{c|c|c|c|c|c|c}
\hline & \multicolumn{3}{|c|}{ CR3022 } & \multicolumn{3}{c}{ eCR3022.20 } \\
\hline & Resi. No. & $\Phi\left(^{\circ}\right)$ & $\Psi\left(^{\circ}\right)$ & Resi. No. & $\Phi\left(^{\circ}\right)$ & $\Psi\left(^{\circ}\right)$ \\
\hline $\mathrm{i}$ & P52a & -69 & -34 & P52a & -64 & -23 \\
\hline $\mathrm{i}+1$ & G53 & -62 & -40 & G53 & -66 & -35 \\
\hline $\mathrm{i}+2$ & D54 & -133 & 11 & D54 & -136 & 3 \\
\hline $\mathrm{i}+3$ & S55 & 59 & 42 & G55 & 80 & 15 \\
\hline
\end{tabular}
Figure S9. CDR H2 of CR3022 and eCR3022.20 form a type IV $\boldsymbol{\beta}$ turn. Related to Figure 3. (A-B) Comparison between the H2 CDRs of (A) CR3022 and (B) eCR3022.20. Residues that differ are highlighted in red letters. Our previous structure of CR3022 (PDB ID: 6W41) and the structure of eCR3022.20 are used for the comparison. (C-D) Ramachandran plots of the H2 CDRs of (C) CR3022 and (D) eCR3022.20 indicate type-IV $\beta$ turns $\left(V_{H}{ }^{52 a P G D S}{ }^{55}\right)$ for both H2 CDR loops are they deviate slightly from a type $1 \beta$ turn. Phi and psi angles of the residues $i+1$ (G53) and i+2 (D54) are shown as blue circles and red squares, respectively. 
A

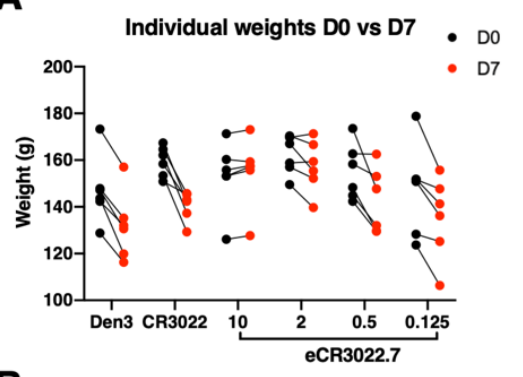

B

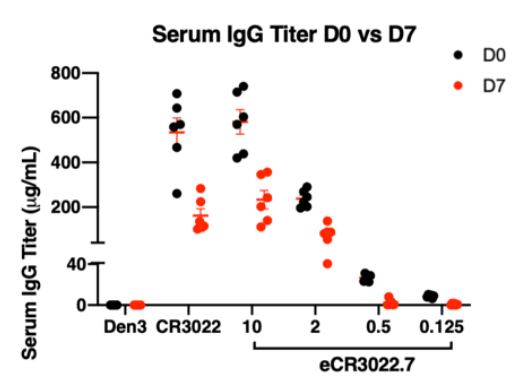

C

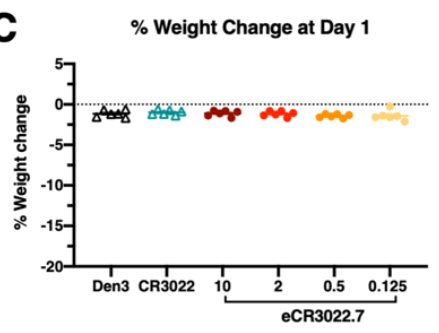

\% Weight Change at Day 2

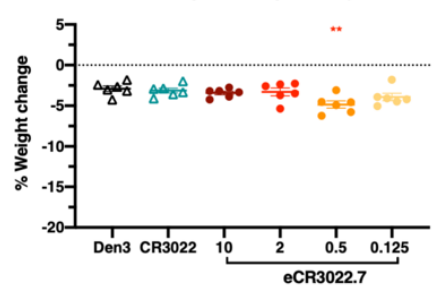

$\%$ Weight Change at Day 3

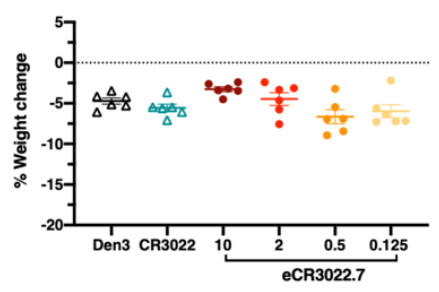

\% Weight Change at Day 4

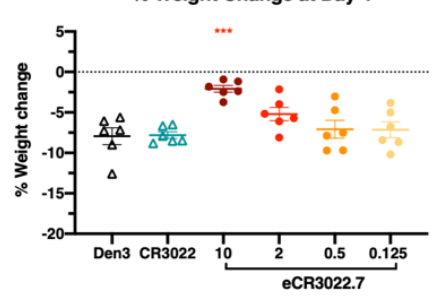

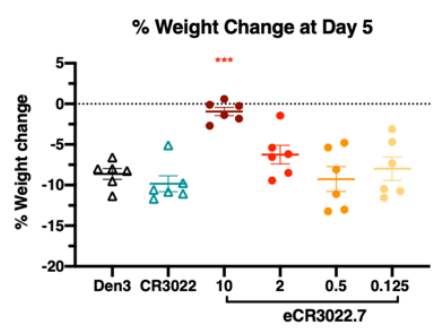

\% Weight Change at Day 6

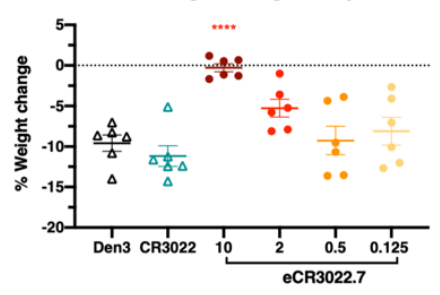

$\%$ Weight Change at Day 7

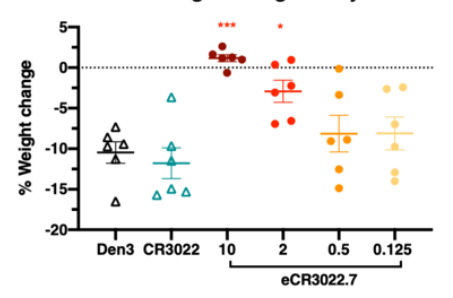

Figure S10. Animal protection studies. Related to Figure 4. (A) Weights of animals at time of challenge (Day 0) compared to weights at time of sacrifice (Day 7). (B) Serum human IgG concentration at time of infection (Day 0) compared to sacrifice (Day 7). (C) Percent weight loss by day compared to weights recorded at time of infection at day 0 . 
A Receptor-binding site
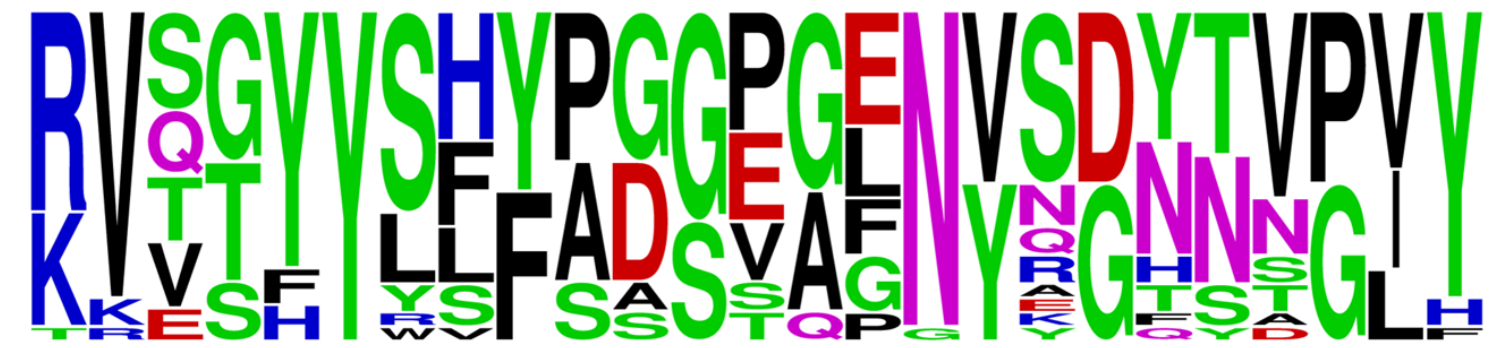

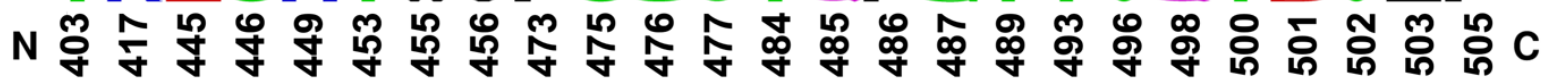

B eCR3022.20 epitope

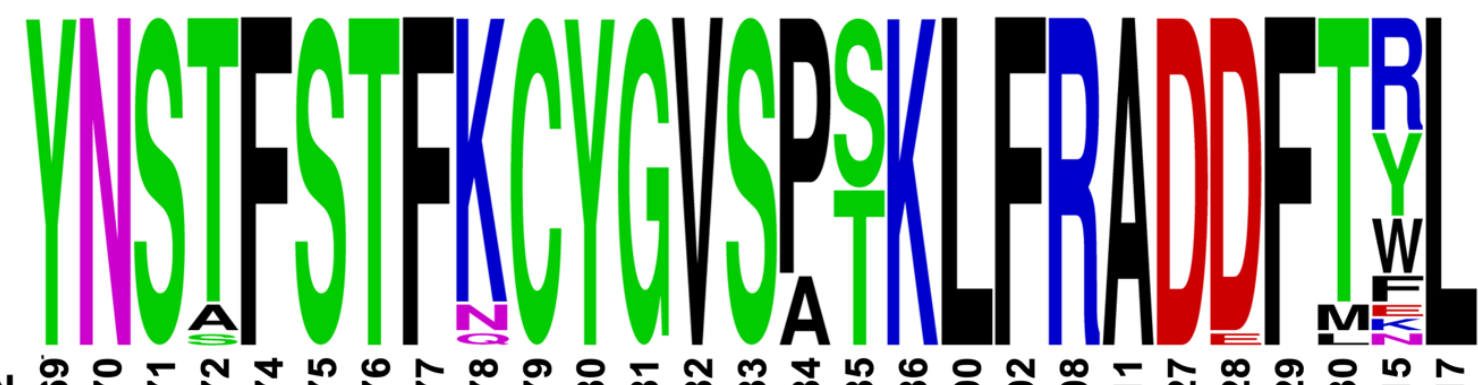

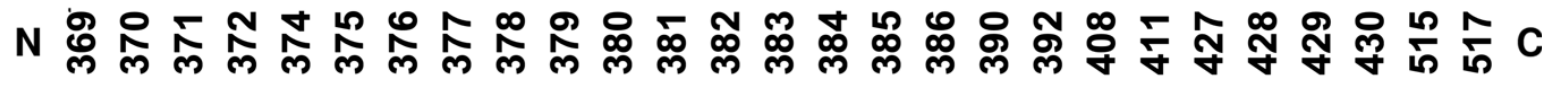

Figure S11. Sequence conservation of the eCR3022.20 epitope versus the SARS-CoV RBS.

Residues that interact with (A) ACE2 and (B) eCR3022.20 (defined by BSA $>0 \AA^{2}$ ) are shown as

a sequence logo (Crooks et al., 2004). BSA values are calculated with PISA (Krissinel and

578 Henrick, 2007) using the SARS-CoV-2 RBD/ACE2 structure (PDB 6MOJ) (Lan et al., 2020) and

579 the CR3022.20/RBD structure determined here. Sequences of 22 Sarbecoviruses including 580 SARS-CoV-2, SARS-CoV and SARS-related coronaviruses (SARSr-CoVs) were used for this 581 analysis: NCBI Reference Sequence YP_009724390.1 (SARS-CoV-2), GenBank ABF65836.1 582 (SARS-CoV), GenBank ALK02457.1 (Bat SARSr-CoV WIV16), GenBank AGZ48828.1 (Bat 583 SARSr-CoV WIV1), GenBank ACU31032.1 (Bat SARSr-CoV Rs672), GenBank AIA62320.1 (Bat 584 SARSr-CoV GX2013), GenBank AAZ67052.1 (Bat SARSr-CoV Rp3), GenBank AIA62300.1 (Bat 585 SARSr-CoV SX2013), GenBank ABD75323.1 (Bat SARSr-CoV Rf1), GenBank AIA62310.1 (Bat 586 SARSr-CoV HuB2013), GenBank AAY88866.1 (Bat SARSr-CoV HKU3-1), GenBank AID16716.1 587 (Bat SARSr-CoV Longquan-140), GenBank AVP78031.1 (Bat SARSr-CoV ZC45), GenBank 588 AVP78042.1 (Bat SARSr-CoV ZXC21), GenBank QHR63300.2 (Bat CoV RaTG13), NCBI 589 Reference Sequence YP_003858584.1 (Bat SARSr-CoV BM48-31), GISAID EPI_ISL_410721 590 (Pangolin-CoV Guandong2019), GenBank QIA48632.1 (Pangolin-CoV Guangxi), GenBank 591 AGZ48806.1 (Bat SARSr-CoV RsSHC0144), GenBank ATO98120.1 (Bat SARSr-CoV Rs4081), 


\section{MATERIALS AND METHODS}

596 Antibody library generation

597 CR3022 heavy chain and light chain affinity maturation libraries were synthesized by Twist 598 Bioscience (San Francisco). Mutations were included in the CDR loops, based on the following definitions: CDRH1 = GYGFITYWI, CDRH2 = IIYPGDSET, CDRH3 = GGSGISTPMDV, CDRL1 $=$ VLYSSINKNYL, CDRL2 = IYWASTRE, CDRL3 = QQYYSTPY. At each position in the CDR loop, mini libraries were synthesized that encoded all possible single mutations from the starting sequence, excluding variants where the substitution was to a cysteine or methionine and variants that created an N-linked glycosylation motif. The CDR1/2/3 mini-libraries were assembled into combinatorial heavy chain and light chain libraries.

605 The libraries were displayed on the surface of yeast as molecular Fab using the pYDSI vector, a 606 yeast display vector containing the bidirectional Gal1-10 promoter that was based on the design 607 of a previously described vector (Wang et al., 2018), omitting the leucine-zipper dimerization 608 domains. The heavy chain contains a C-terminal V5 epitope tag and the light chain contains a C609 terminal C-myc epitope tag to assess the amount of Fab displayed on the surface of the yeast.

610 The $\mathrm{HC}$ library was generated by cloning the HC CDR1/2/3 library into a vector already containing 611 the invariant CR3022 light chain by homologous recombination, and the LC library was generated 612 by doing the inverse. The HC/LC library was generated by amplifying the HC and LC sequences 613 with primers overlapping in the Gal1-10 promoter. The recovered Gal-HC and Gal-LC fragments 614 were ligated via Gibson assembly and amplified. The resulting LC-Gal1-10-HC product was 615 cloned into empty pYDSI by homologous recombination.

\section{Yeast transformation}

618 Yeast transformation was performed as described previously. In brief, the colony of 619 Saccharomyces cerevisiae YVH10 cells (ATCC, MYA4940) was inoculated in 2mL YPD medium 620 (Dissolve $20 \mathrm{~g}$ dextrose, $20 \mathrm{~g}$ peptone and $10 \mathrm{~g}$ yeast extract in deionized $\mathrm{H}_{2} \mathrm{O}$ to a volume of 1 621 liter and sterilize by filtration) and shaken overnight at $30^{\circ} \mathrm{C}$. The overnight culture was expanded 622 in $50 \mathrm{~mL}$ YPD medium and shaken at $30^{\circ} \mathrm{C}$ until the absorbance was around 1.5 at $600 \mathrm{~nm}$. Yeast 623 cells were spun down and resuspended with $25 \mathrm{~mL}$ of $100 \mathrm{mM}$ lithium acetate. $250 \mu \mathrm{L}$ of $1 \mathrm{M}$ 
624 DTT was added to the cells and mixed rapidly. After shaking at $30^{\circ} \mathrm{C}$ for $10 \mathrm{~min}$, cells were spun 625 down and washed with $25 \mathrm{~mL}$ of pre-chilled deionized $\mathrm{H}_{2} \mathrm{O}$. After centrifuge, the cell pellet was 626 suspended with pre-chilled deionized $\mathrm{H}_{2} \mathrm{O}$ to a final volume of $500 \mu \mathrm{L}$. After this step, yeast cells 627 were electrocompetent and ready for transformation.

$6281 \mu \mathrm{g}$ of linearized vector DNA was mixed with $5 \mathrm{ug}$ of insert library DNA in an Eppendorf tube on 629 ice. $250 \mu \mathrm{L}$ of electrocompetent cells were transferred to the tube and incubated for $10 \mathrm{~min}$ on 630 ice. Then the cells and DNA mixture were transferred to cuvette and inserted into Gene Pulser 631 Xcell Electroporation System (Biorad) using following settings:

632 Square wave

633 Voltage $=500 \mathrm{~V}$

634 Pulse length $=15.0 \mathrm{~ms}$

$635 \quad \#$ pulses $=1$

636 Pulse interval $=0$

637 Cuvette $=2 \mathrm{~mm}$

638 After electrophoresis, cells were shocked by immediately adding $1 \mathrm{~mL}$ of pre-warmed YPD 639 medium. Cells were then transferred to a $50 \mathrm{~mL}$ tube for outgrowth. After shaking $200 \mathrm{rpm}$ at $64030^{\circ} \mathrm{C}$ for $1 \mathrm{~h}$, cells were centrifuged and resuspended in synthetic drop-out medium without 641 tryptophan (with $1 \%$ Penicillin/Streptomycin) and shaken overnight to grow.

\section{Yeast library labeling and sorting}

644 After yeast transformation, yeast cells were expanded and split once for better display efficiency. 645 Before staining, cells were induced overnight at $30^{\circ} \mathrm{C}$ by SGCAA induction medium (dissolve 20 $646 \mathrm{~g}$ galactose, $1 \mathrm{~g}$ glucose, $6.7 \mathrm{~g}$ yeast nitrogen base without amino acid, $5 \mathrm{~g}$ bacto casamino acids, $6475.4 \mathrm{~g} \mathrm{Na}_{2} \mathrm{HPO}_{4}, 8.56 \mathrm{~g} \mathrm{NaH}_{2} \mathrm{PO}_{4} \bullet \mathrm{H}_{2} \mathrm{O}, 8.56 \mathrm{mg}$ uracil to $1 \mathrm{~L}$ deionized water, $\mathrm{pH}$ 6.5, and sterilize 648 by filtration). For each library, in the first round of selection, $5 \times 10^{7}$ of yeast cells were stained per 649 sample. In the second to final round of selection, $1 \times 10^{7}$ cells were stained. Yeast cells were 650 firstly spun down and washed with PBS/1\% BSA, then incubated with biotinylated SARS-CoV-2 651 RBD or S or HEK cell membrane protein at several non-depleting concentrations respectively for 652 at least $30 \mathrm{~min}$ at $4^{\circ} \mathrm{C}$. After washing, yeast cells were stained with FITC-conjugated chicken anti653 C-Myc antibody (Immunology Consultants Laboratory, CMYC-45F), AF405-conjugated anti-V5 654 antibody (made in house), and streptavidin-APC (Invitrogen, SA1005) in 1:100 dilution for 20 min 655 at $4{ }^{\circ} \mathrm{C}$. After washing, yeast cells were resuspended in $1 \mathrm{~mL}$ of PBS/1\% BSA and loaded on BD 656 FACSMelody cell sorter. Top 5-10\% of cells with high binding activity to a certain SARS-CoV-2 
657 RBD labeling concentration were sorted and spun down. Sorted cells were expanded in $2 \mathrm{~mL}$ of 658 synthetic drop-out medium without tryptophan (Sigma-Aldrich, Y1876-20G) supplemented with $6591 \%$ Penicillin/Streptomycin (Corning, 30-002-C) at $30^{\circ} \mathrm{C}$ overnight.

\section{Deep sequencing and analysis}

662 After each sort, a fragment of cell population was expanded in $2 \mathrm{~mL}$ of synthetic drop-out medium 663 without tryptophan supplemented with $1 \%$ Penicillin/Streptomycin overnight at $30^{\circ} \mathrm{C}$. Yeast cells 664 were then spun down, cell pellet was resuspended with $250 \mu \mathrm{L}$ of buffer P1 (with RNAse added) 665 (Qiagen, 27104) by pipetting up and down. $5 \mu \mathrm{L}$ of Zymolyase (Zymo Research, E1005) was 666 added to digest yeast cell walls and incubated at $37^{\circ} \mathrm{C}$ for $1 \mathrm{~h}$. Cells were then lysed, neutralized, 667 and DNA was purified according to manufacturer's instructions (Qiagen, 27104). After that, 668 CR3022 HC and LC fragments from post-sorted plasmid DNA were amplified by following 669 CR3022-HC and CR3022-LC primer mixture respectively.

670 CR3022.HC-

671 NGSFa:GTCTCGTGGGCTCGGAGATGTGTATAAGAGACAGGAGTCTCTGAAGATCTCCTGT

672 AAGGG;

673 CR3022.HC-

674 NGSFb:GTCTCGTGGGCTCGGAGATGTGTATAAGAGACAGHHGAGTCTCTGAAGATCTCCT 675 GTAAGGG;

676 CR3022.HC-

677 NGSFc:GTCTCGTGGGCTCGGAGATGTGTATAAGAGACAGHHHHGAGTCTCTGAAGATCTC 678 CTGTAAGGG;

679 CR3022.HC-

680 NGSRa:TCGTCGGCAGCGTCAGATGTGTATAAGAGACAGGAGACGGTGACCGTGGTTC;

681 CR3022.HC-

682 NGSRb:TCGTCGGCAGCGTCAGATGTGTATAAGAGACAGHHGAGACGGTGACCGTGGTTC;

683 CR3022.HC-

684 NGSRc:TCGTCGGCAGCGTCAGATGTGTATAAGAGACAGHHHHGAGACGGTGACCGTGGT 685 TC;

686 CR3022.LC-

687 NGSFa:GTCTCGTGGGCTCGGAGATGTGTATAAGAGACAGGGAGAAAGAGCCACCATCAAC 688 TG; 
692 CR3022.LC-

693 NGSFc:GTCTCGTGGGCTCGGAGATGTGTATAAGAGACAGHHHHGGAGAAAGAGCCACCAT

694 CAACTG;

695 CR3022.LC-

696 NGSRa:TCGTCGGCAGCGTCAGATGTGTATAAGAGACAGGATCTCCACCTTGGTCCCTTG;

697 CR3022.LC-

698 NGSRb:TCGTCGGCAGCGTCAGATGTGTATAAGAGACAGHHGATCTCCACCTTGGTCCCTT

699 G;

700 CR3022.LCNGSRc:TCGTCGGCAGCGTCAGATGTGTATAAGAGACAGHHHHGATCTCCACCTTGGTCCC TTG.

$1 \mu \mathrm{L}$ of primer mixture $(10 \mu \mathrm{M})$ were used to amplify the $\mathrm{HC}$ and LC DNA respectively after every round of FACS selection with $2 \mu \mathrm{L}$ of post-sorted plasmid DNA, $10 \mu \mathrm{L}$ of $5 \mathrm{X}$ Phusion HF buffer, $35.5 \mu \mathrm{L}$ of $\mathrm{H}_{2} \mathrm{O}$, and $0.5 \mu \mathrm{L}$ of Phusion enzyme (ThermoFisher, F530L) using the following PCR program: $1 \mathrm{~min}$ at $98^{\circ} \mathrm{C} ; 32$ cycles of $10 \mathrm{~s}$ at $98^{\circ} \mathrm{C}, 15 \mathrm{~s}$ at $65^{\circ} \mathrm{C}, 30 \mathrm{~s}$ at $72^{\circ} \mathrm{C}$; followed by $5 \mathrm{~min}$ at $72^{\circ} \mathrm{C}$. After PCR clean up, second round of PCR was performed by adding $2 \mu \mathrm{L}$ of first round PCR product, $5 \mu \mathrm{L}$ of $4 \mu \mathrm{M}$ barcode nextera adapter primer mixture, $0.4 \mathrm{uL}$ of $10 \mathrm{mM}$ dNTP, $4 \mathrm{uL}$ of $5 X$ Phusion HF buffer (ThermoFisher, F518L), $8.4 \mu \mathrm{L}$ of $\mathrm{H}_{2} \mathrm{O}$, and $0.2 \mu \mathrm{L}$ of Phusion enzyme and using the following PCR program: $1 \mathrm{~min}$ at $98^{\circ} \mathrm{C} ; 7$ cycles of $15 \mathrm{~s}$ at $98^{\circ} \mathrm{C}, 15 \mathrm{~s}$ at $68^{\circ} \mathrm{C}, 30 \mathrm{~s}$ at $72^{\circ} \mathrm{C}$; followed by $5 \mathrm{~min}$ at $72^{\circ} \mathrm{C}$. After PCR clean up, all the PCR products were combined and diluted to $15 \mathrm{pM}$ in the final volume of $20 \mu \mathrm{L}$. To denature the DNA, $5 \mu \mathrm{L}$ of the diluted library and

$7135 \mu \mathrm{L}$ of freshly-prepared $0.2 \mathrm{~N} \mathrm{NaOH}$ were mixed and incubated at room temperature for $5 \mathrm{~min}$.

714 Then $990 \mu \mathrm{L}$ of pre-chilled HyB buffer was added and mixed well. $570 \mu \mathrm{L}$ of denatured library 715 DNA and $30 \mu \mathrm{L}$ of denatured PhiX control library (Illumina, FC-110-3001) were mixed, added into 716 Miseq Reagent V3 kit (Illumina, MS-102-3003), and finally loaded onto Illumina Miseq Next 717 Generation sequencer.

718 Paired FASTQs were checked for sequence quality using the FastQC package (FastQC v0.11.9). 719 The forward and reverse reads were merged using BBMerge (version 38.87) from the BBTools 720 suite using standard parameters (Bushnell et al., 2017). Merged reads with full sequence identity 721 were clustered using VSEARCH (v2.15.1) (Rognes et al., 2016). Clustering was done using the 722 "cluster_fast" method and fasta files were written including cluster abundance in the fasta header. 
723 A custom python (Python 3.7) script was written to parse the vsearch output, translate the DNA

724 sequences to amino acid sequences and count the CDR1, CDR2, and CDR3 positions. Using

725 VSEARCH for clustering prior to translating and parsing the sequences improved performance

726 substantially.

728 Pacbio sequencing

729 Long Amp Taq Polymerase (New England Biolabs) was used to PCR amplify Plasmid DNA after

730 sort 4 according to manufacturer's protocol with the following primers:

731 CR3022_PCR1_FWD:

732 /5AmMC6/GCAGTCGAACATGTAGCTGACTCAGGTCACCAAACAACAGAAGCAGTCCCA

733 CR3022_PCR1_REV:

734 I5AmMC6/TGGATCACTTGTGCAAGCATCACATCGTAGGGAGTTCAGGTGCTGGTGAT.

736 First round PCR products were purified with SPRI beads (Beckman Coulter) and $10 \mathrm{uL}$ of purified

737 PCR product was used in a second round of index PCR with the following primers:

738 bc_1004_FWD_PacB_Univ.PCR:

739 GGGTCACGCACACACGCGCGgcagtcgaacatgtagctgactcaggtcac

740 bc_1028_REV_PacB_Univ.PCR:

741 CAGTGAGAGTCAGAGCAGAGtggatcacttgtgcaagcatcacatcgtag

743 DNA sample was again purified with SPRI beads, then submitted to GeneWiz, where a PacBio

744 SMRTbell amplicon library was prepared per the manufacturer's protocol and sequenced on the

745 PacBio Sequel platform with v3.0 chemistry. The generated subreads were demultiplexed and

746 circular consensus sequence (CCS) reads were obtained using the CCS algorithm within PacBio

747 ccs v4.2.0. The algorithm was run using the default parameters. A custom python (Python 3.7)

748 script was written to parse the CCS fastq output, translate the DNA sequences to amino acid

749 sequences and count the CDR1, CDR2, and CDR3 positions.

750

751 Sequence data that support the findings in this study are available at the NCBI Sequencing Read

752 Archive (www.ncbi.nlm.nih.gov/sra) under BioProject number PRJNAXXXXXX. Python code will

753 be available on github.

755 Recombinant S and RBD production 

were transiently expressed in Freestyle 293F system (ThermoFisher). In brief, $S$ or RBD expression plasmids were cotransfected with $40 \mathrm{~K} \mathrm{PEI}(1 \mathrm{mg} / \mathrm{mL})$ at a ratio of $1: 3$. After incubation for $30 \mathrm{~min}$ at RT, transfection mixture was added to Freestyle 293F cells at a density of approximately 1 million cells $/ \mathrm{mL}$. After 5 days, supernatants were harvested and filtered with a $0.22 \mu \mathrm{m}$ membrane. The His-tagged proteins were purified with the HisPur Ni-NTA Resin (Thermo

762 Fisher, 88222). After three columns of washing with $25 \mathrm{mM}$ Imidazole ( $\mathrm{pH} 7.4)$, proteins were 763 eluted with an elution buffer (250 mM Imidazole, $\mathrm{pH} 7.4)$ at slow gravity speed ( 4 sec/drop).

764 Eluted proteins were buffer exchanged and concentrated with PBS using Amicon tubes

765 (Millipore). The proteins were further purified by size exclusion chromatography (SEC) using 766 Superdex 200 (GE Healthcare). The selected fractions were pooled and concentrated again for 767 further use.

\section{Antibody production and purification}

770 Monoclonal antibody was transiently expressed in the Expi293 system (ThermoFisher, A14635).

771 In brief, antibody HC and LC plasmids were co-transfected at a ratio of 1:2.5 with transfection reagent FectoPRO (Polyplus 116-010). After $24 \mathrm{~h}$ of transfection, $300 \mathrm{mM}$ of sterile sodium

773 valproic acid solution (Sigma-Aldrich, P4543) and 45\% D-(+)- glucose solution (Sigma Aldrich,

774 G8769-100ML) were added to feed cells. After 4-5 days of transfection, supernatants were 775 collected, sterile-filtered $(0.22 \mu \mathrm{m})$, and IgG was purified with Protein A sepharose beads (GE 776 Healthcare 17-5280-04).

\section{Pseudovirus neutralization assay}

779 Pseudovirus was generated as described previously ${ }^{2}$. In brief, $12.5 \mu \mathrm{g}$ of MLV gag/pol backbone

780 (Addgene, 14887), $10 \mu \mathrm{g}$ of MLV-CMV-Luciferase plasmid, and $2.5 \mu \mathrm{g}$ of SARS-CoV-2-d18 spike 781 plasmid were incubated with transfection reagent Lipofectamine 2000 (Thermo Fisher, 11668027)

782 following manufacturer's instructions for 20 min at RT. Then the mixture was transferred onto HEK 783 293T cells (ATCC, CRL-3216) in a $10 \mathrm{~cm}^{2}$ culture dish (Corning, 430293). After 12-16 h of 784 transfection, culture medium was gently removed, fresh DMEM medium was added onto the 785 culture dish. Supernatants containing pseudovirus were harvested after $48 \mathrm{~h}$ post transfection 786 and frozen at $-80{ }^{\circ} \mathrm{C}$ for long term storage.

787 In the neutralization assay, antibody samples were serially diluted with complete DMEM medium 788 (Corning, 15-013-CV) containing 10\% FBS (Omega Scientific, FB-02), 2 mM L-Glutamine 789 (Corning, 25-005-Cl), and $100 \mathrm{U} / \mathrm{mL}$ of Penicillin/Streptomycin (Corning, 30-002-C). $25 \mu \mathrm{L} /$ well of 
790 diluted samples were then incubated with $25 \mu \mathrm{L} /$ well of pseudotyped virus for $1 \mathrm{~h}$ at $37^{\circ} \mathrm{C}$ in 96 791 well half-area plates (Corning, 3688). After that, $50 \mu \mathrm{L}$ of Hela-hACE2 cells were added at 10,000

792 cells/well onto each well of the plates. After $48 \mathrm{~h}$ of incubation, cell culture medium was removed, 793 luciferase lysis buffer (25 mM Gly-Gly pH 7.8, 15 mM MgSO4, 4 mM EGTA, 1\% Triton X-100) 794 was added onto cells. Luciferase activity was measured by BrightGlo substrate (Promega, PR795 E2620) according to the manufacturer's instructions. mAbs were tested in duplicate wells and 796 independently repeated at least twice. Neutralization $\mathrm{IC}_{50}$ values were calculated using "One-Site 797 Fit LogIC50" regression in GraphPad Prism 8.0.

\section{Authentic SARS-CoV-2 neutralization assay}

800 Vero E6 cells were seeded in 96-well half-well plates at approximately 8000 cells/well in a total 801 volume of $50 \mu \mathrm{L}$ complete DMEM medium the day prior to the addition antibody and virus mixture. 802 The virus (500 plaque forming units/well) and antibodies were mixed, incubated for 30 minutes 803 and added to the cells. The transduced cells were incubated at $37^{\circ} \mathrm{C}$ for 24 hours. Each treatment 804 was tested in duplicate. The medium was removed and disposed of appropriately. Cells were 805 fixed by immersing the plate into $4 \%$ formaldehyde for 1 hour before washing 3 times with 806 phosphate buffered saline (PBS). The plate was then either stored at $4^{\circ} \mathrm{C}$ or gently shaken for 30 807 minutes with $100 \mu \mathrm{L} /$ well of permeabilization buffer (PBS with 1\% Triton-X). All solutions were 808 removed, then $100 \mu \mathrm{l}$ of $3 \%$ bovine serum albumin (BSA) was added, followed by room 809 temperature (RT) incubation at 2 hours.

810 Primary antibodies against the spike protein were generated from a high-throughput process that 811 screened a convalescent, coronavirus disease 2019 cohort (CC) $)^{2}$. A mix of primary antibodies 812 consisting of CC6.29, CC6.33, CC6.36, CC12.23, CC12.25, in a 1:1 ratio, were used next. The 813 primary antibody mixture was diluted in PBS $/ 1 \%$ BSA to a final concentration of $2 \mu \mathrm{g} / \mathrm{ml}$. The 814 blocking solution was removed and washed thoroughly with wash buffer (PBS with $0.1 \%$ Tween815 20). The primary antibody mixture, $50 \mu \mathrm{l} /$ well, was incubated with the cells for 2 hours at RT. The 816 plates were washed 3 times with wash buffer.

817 Peroxidase AffiniPure Goat Anti-Human $\lg \mathrm{H}(\mathrm{H}+\mathrm{L})$ secondary antibody (Jackson 818 ImmunoResearch, 109-035-088) diluted to $0.5 \mu \mathrm{g} / \mathrm{mLI}$ in PBS/1\% BSA was added at $50 \mu \mathrm{L} /$ well 819 and incubated for 2 hours at RT. The plates were washed 6 times with wash buffer. HRP substrate 820 (Roche, 11582950001) was freshly prepared as follows: Solution A was added to Solution B in a 821 100:1 ratio and stirred for 15 minutes at RT. The substrate was added at $50 \mu \mathrm{L} /$ well and 822 chemiluminescence was measured in a microplate luminescence reader (BioTek, Synergy 2). 
823 The following method was used to calculate the percentage neutralization of SARS-CoV-2. First, 824 we plotted a standard curve of serially diluted virus $(3000,1000,333,111,37,12,4,1$ PFU) 825 versus RLU using four-parameter logistic regression (GraphPad Prism 8.0) below:

826

(y: RLU, x: PFU, a,b,c and x0 are parameters fitted by standard curve)

$$
y=a+\frac{b-a}{1+\left(\frac{x}{x_{0}}\right)^{c}}
$$

To convert sample RLU into PFU, use the equation below: (if $y<a$ then $x=0$ )

$$
x=x_{0} \log _{c} \frac{b-y}{y-a}
$$

Percentage neutralization was calculated by the following equation:

$$
\% \text { Neut }=100 \times \frac{\mathrm{VC}-\mathrm{nAb}}{\mathrm{VC}-\mathrm{CC}}
$$

$\mathrm{VC}=$ Average of vehicle-treated control; $\mathrm{CC}=$ Average of cell only control, nAb, neutralizing antibody. PFU value was used for each variable indicated.

To compute neutralization $\mathrm{IC}_{50}$, logistic regression (sigmoidal) curves were fit using GraphPad Prism. Means and standard deviations are displayed in the curve fit graphs and were also calculated using GraphPad Prism 8.0.

\section{Recombinant protein ELISAs}

6x-His tag antibodies were coated at $2 \mathrm{ug} / \mathrm{mL}$ in PBS onto 96-well half-area high binding plates (Corning, 3690) overnight at $4^{\circ} \mathrm{C}$ or $2 \mathrm{~h}$ at $37^{\circ} \mathrm{C}$. After washing, plates were blocked with $3 \% \mathrm{BSA}$ 
851 Solubilized $\mathrm{CHO}$ cell membrane protein (SMP), human insulin (Sigma-Aldrich, I2643), single 852 strand DNA (Sigma-Aldrich, D8899) were coated onto 96-well half-area high-binding ELISA plates

853 (Corning, 3690) at $5 \mathrm{ug} / \mathrm{mL}$ in PBS overnight at $4^{\circ} \mathrm{C}$. After washing, plates were blocked with 854 PBS $/ 3 \%$ BSA for $1 \mathrm{~h}$ at RT. Antibody samples were diluted at $100 \mathrm{ug} / \mathrm{mL}$ in $1 \%$ BSA with 5 -fold 855 serial dilution. Serially diluted samples were then added in plates and incubated for $1 \mathrm{~h}$ at RT. 856 After washing, alkaline phosphatase-conjugated goat anti-human IgG Fcy secondary antibody 857 (Jackson ImmunoResearch, 109-055-008) was added in 1:1000 dilution and incubated for $1 \mathrm{~h}$ at 858 RT. After final wash, phosphatase substrate (Sigma-Aldrich, S0942-200TAB) was added into 859 each well. Absorption was measured at $405 \mathrm{~nm}$.

\section{HEp2 epithelial cell polyreactive assay}

862 Reactivity to human epithelial type 2 (HEp2) cells was determined by indirect 863 immunofluorescence on HEp2 slides (Hemagen, 902360) according to manufacturer's 864 instructions. In brief, monoclonal antibody was diluted at $100 \mathrm{ug} / \mathrm{mL}$ in PBS and then incubated 865 onto immobilized HEp2 slides for $30 \mathrm{~min}$ at RT. After washing, one drop of FITC-conjugated goat 866 anti-human IgG was added onto each well and incubated in the dark for 30 min at RT. After washing, cover slide was added to HEp2 cells with glycerol and the slide was photographed on a Nikon fluorescence microscope to detect GFP. All panels were shown at magnification 40x.

\section{Surface plasmon resonance methods}

871 SPR measurements were carried out on a Biacore $8 \mathrm{~K}$ instrument at $25^{\circ} \mathrm{C}$. All experiments were 872 carried out with a flow rate of $30 \mu \mathrm{L} / \mathrm{min}$ in a mobile phase of HBS-EP [0.01 M HEPES (pH 7.4), $8730.15 \mathrm{M} \mathrm{NaCl}, 3 \mathrm{mM}$ EDTA, $0.0005 \%$ (v/v) Surfactant P20]. Anti-Human IgG (Fc) antibody (Cytiva) 874 was immobilized to a density $\sim 7000-10000 \mathrm{RU}$ via standard NHS/EDC coupling to a Series S 875 CM-5 (Cytiva) sensor chip. A reference surface was generated through the same method.

876 For conventional kinetic/dose-response, listed antibodies were captured to 50-100 RU via Fc877 capture on the active flow cell prior to analyte injection. A concentration series of SARS-CoV-2 878 RBD was injected across the antibody and control surface for 2 min, followed by a 5 min 879 dissociation phase using a multi-cycle method. Regeneration of the surface in between injections 880 of SARS-CoV-2 RBD was achieved by a single, 120 s injection of $3 \mathrm{M} \mathrm{MgCl}$. Kinetic analysis of 881 each reference subtracted injection series was performed using the BIAEvaluation software 882 (Cytiva). All sensorgram series were fit to a 1:1 (Langmuir) binding model of interaction. 


\section{Expression and purification of Fab}

884 The CC12.3 Fab was expressed and purified using a previous protocol (Yuan et al., 2020b). In 885 brief, the heavy and light chains were cloned into phCMV3. The plasmids were transiently co886 transfected into ExpiCHO cells at a ratio of 2:1 (HC:LC) using ExpiFectamine ${ }^{\mathrm{TM}} \mathrm{CHO}$ Reagent 887 (Thermo Fisher Scientific) according to the manufacturer's instructions. The supernatant was 888 collected at 10 days post-transfection. The Fabs were purified with a CaptureSelect ${ }^{\mathrm{TM}} \mathrm{CH} 1-\mathrm{XL}$ 889 Affinity Matrix (Thermo Fisher Scientific) followed by size exclusion chromatography. The 890 eCR3022.20 Fab was purified by digesting eCR3022.20 lgG using Fab digestion kit 891 (ThermoFisher, 44985) according to manufacturer's instructions. After digestion, Fc fragments 892 and undigested IgG were removed from binding to the protein A beads. The unbound flowthrough 893 Fab was collected and followed by size exclusion chromatography.

\section{Crystal structure determination of the eCR3022.20-RBD-CC12.3 complex} Purified eCR3022.20 Fab, CC12.3 Fab, and SARS-CoV-2 RBD were mixed at an equimolar ratio and incubated overnight at $4^{\circ} \mathrm{C}$. The complex $(12 \mathrm{mg} / \mathrm{ml})$ was screened for crystallization using the 384 conditions of the JCSG Core Suite (Qiagen) on our custom-designed robotic CrystalMation system (Rigaku) at Scripps Research by the vapor diffusion method in sitting drops containing $0.1 \mu \mathrm{l}$ of protein and $0.1 \mu \mathrm{l}$ of reservoir solution. Optimized crystals were then grown in $0.1 \mathrm{M}$ sodium citrate - citric acid buffer $\mathrm{pH} 5.0,15 \%(\mathrm{v} / \mathrm{v})$ ethylene glycol, $1 \mathrm{M}$ lithium chloride, and $10 \%(\mathrm{w} / \mathrm{v})$ polyethylene glycol 6000 at $20^{\circ} \mathrm{C}$. Crystals were grown for 7 days and then flash cooled

903 in liquid nitrogen. Diffraction data were collected at cryogenic temperature $(100 \mathrm{~K})$ at the Stanford 904 Synchrotron Radiation Lightsource (SSRL) on the Scripps/Stanford beamline 12-1 with a 905 wavelength of $0.97946 \AA$, and processed with HKL2000 (Otwinowski and Minor, 1997). Structures 906 were solved by molecular replacement using PHASER (McCoy et al., 2007) with PDB 6XC7(Yuan 907 et al., 2020b). Iterative model building and refinement were carried out in COOT (Emsley et al., 908 2010) and PHENIX (Adams et al., 2010), respectively.

\section{Data availability}

911 Crystal structure data and coordinates will be deposited in the PDB prior to publication.

\section{$912 \quad$ Animal study}

913 Groups of twelve 6-8 week old Syrian hamsters were put into 6 treatment groups who each 914 received an intraperitoneal (i.p.) infusion of either $10 \mathrm{mg}, 2 \mathrm{mg}, 0.5 \mathrm{mg}$, or $0.125 \mathrm{mg}$ per animal 915 of the eCR3022.7 monoclonal antibody or $10 \mathrm{mg}$ per animal of the parental CR3022 monoclonal 
916 antibody or $10 \mathrm{mg}$ per animal of an anti-dengue isotype matched control antibody (Den3). After

91772 hours, serum was obtained to quantify mAb titers prior to animal infection. Each hamster was

918 then infected through intranasal administration of $10^{\wedge} 5$ total PFU (plaque forming units) of SARS-

919 CoV-2 (USA-WA1/2020). Animal weights were obtained during the study as a measure of disease

920 progression. On day four post infection, six of the animals were sacrificed and lung tissue was

921 harvested for viral titer analysis by RT-qPCR as well as live viral titers via plaque assay. At day

922 seven post-infection, six of the animals were sacrificed and serum was collected to assess mAb

923 titer at the time of sacrifice using our recombinant protein ELISA protocol. Research protocol was

924 approved and performed in accordance with Scripps Research IACUC Protocol \#20-0003.

\section{Viral load measurements - Plaque Assay}

926 SARS-CoV-2 titers were measured by homogenizing lung tissue in DMEM 2\% FCS using $100 \mu \mathrm{m}$

927 cell strainers (Myriad, 2825-8367). Homogenized organs were titrated 1:10 over 6 steps and 928 layered over Vero-E6 cells. After $1 \mathrm{~h}$ of incubation at $37^{\circ} \mathrm{C}$, a $1 \%$ methylcellulose in DMEM overlay 929 was added, and the cells were incubated for 3 days at $37^{\circ} \mathrm{C}$. Cells were fixed with $4 \%$ PFA and 930 plaques were counted by crystal violet staining.

\section{Statistical methods}

932 Statistical analysis was performed using Graph Pad Prism 8 for Mac, Graph Pad Software, San 933 Diego, California, USA. Groups of data were compared using several methods including the 934 grouped parametric One-Way ANOVA test and the grouped non-parametric Kruskall-Walli test. 935 Data were considered statistically significant at $p<0.05$. 